\title{
Epithelial, metabolic and innate immunity transcriptomic signatures differentiating the rumen from other sheep and mammalian gastrointestinal tract tissues
}

Ruidong Xiang, Victor Hutton Oddy, Alan L. Archibald, Phillip E. Vercoe, Brian P. Dalrymple

Background. Ruminants are successful herbivorous mammals, in part due to their specialized forestomachs, the rumen complex, which facilitates the conversion of feed to soluble nutrients by micro-organisms. Is the rumen complex a modified stomach expressing new epithelial (cornification) and metabolic programs, or a specialised stratified epithelium that has acquired new metabolic activities, potentially similar to those of the colon? How has the presence of the rumen affected other sections of the gastrointestinal tract (GIT) of ruminants compared to non-ruminants? Methods. Transcriptome data from 11 tissues covering the sheep GIT, two stratified epithelial and two control tissues, was analysed using principal components to cluster tissues based on gene expression profile similarity. Expression profiles of genes along the sheep GIT were used to generate a network to identify genes enriched for expression in different compartments of the GIT. The data from sheep was compared to similar data sets from two non-ruminants, pigs (closely related) and humans (more distantly related). Results. The rumen transcriptome clustered with the skin and tonsil, but not the GIT transcriptomes, driven by genes from the epidermal differentiation complex, and genes encoding stratified epithelium keratins and innate immunity proteins. By analysing all of the gene expression profiles across tissues together 16 major clusters were identified. The strongest of these, and consistent with the high turnover rate of the GIT, showed a marked enrichment of cell cycle process genes ( $P=1.4 \mathrm{E}-46)$, across the whole GIT, relative to liver and muscle, with highest expression in the caecum followed by colon and rumen. The expression patterns of several membrane transporters (chloride, zinc, nucleosides, amino acids, fatty acids, cholesterol and bile acids) along the GIT was very similar in sheep, pig and humans. In contrast, short chain fatty acid uptake and metabolism appeared to be different between the species and different between the rumen and colon in sheep. The importance of nitrogen and iodine recycling in sheep was highlighted by the highly preferential expression of SLC14A1-urea (rumen), RHBG-ammonia (intestines) and SLC5A5-iodine (abomasum). The gene encoding a poorly characterized member of the maltase-glucoamylase family (MGAM2), predicted to play a role in the degradation of starch or glycogen, was highly expressed in the small and 
large intestines. Discussion. The rumen appears to be a specialised stratified cornified epithelium, probably derived from the oesophagus, which has gained some liver-like and other specialized metabolic functions, but probably not by expression of pre-existing colon metabolic programs. Changes in gene transcription downstream of the rumen also appear have occurred as a consequence of the evolution of the rumen and its effect on nutrient composition flowing down the GIT. 
1 Epithelial, metabolic and innate immunity transcriptomic signatures

2 differentiating the rumen from other sheep and mammalian gastrointestinal

\section{3 tract tissues}

4

5 Ruidong Xiang ${ }^{1}$, V. Hutton Oddy ${ }^{2}$, Alan L. Archibald ${ }^{3}$, Phillip E. Vercoe ${ }^{4}$, Brian P. Dalrymple ${ }^{1, *}$

$6 \quad{ }^{1}$ CSIRO Agriculture, 306 Carmody Road, St Lucia, QLD 4067, Australia

$7 \quad$ NSW Department of Primary Industries, Beef Industry Centre, University of New England,

8 Armidale, NSW 2351, Australia

$9{ }^{3}$ The Roslin Institute and Royal (Dick) School of Veterinary Studies, University of Edinburgh,

10 Easter Bush, Midlothian EH25 9RG, UK.

$11{ }^{4}$ School of Animal Biology and Institute of Agriculture, The University of Western Australia, 35

12 Stirling Highway Crawley WA 6009, Australia.

13 Email addresses:

14 Ruidong Xiang: ruidong.xiang@csiro.au

15 Hutton Oddy: hutton.oddy@,dpi.nsw.gov.au

16 Alan Archibald: alan.archibald@,roslin.ed.ac.uk

17 Philip E. Vercoe: philip.vercoe@uwa.edu.au 
19 *Brian P. Dalrymple: brian.dalrymple@,csiro.au

$20 *$ : corresponding author 
21 Abstract

22 Background. Ruminants are successful herbivorous mammals, in part due to their specialized

23 forestomachs, the rumen complex, which facilitates the conversion of feed to soluble nutrients by

24 micro-organisms. Is the rumen complex a modified stomach expressing new epithelial

25 (cornification) and metabolic programs, or a specialised stratified epithelium that has acquired

26 new metabolic activities, potentially similar to those of the colon? How has the presence of the

27 rumen affected other sections of the gastrointestinal tract (GIT) of ruminants compared to non-

28 ruminants?

29 Methods. Transcriptome data from 11 tissues covering the sheep GIT, two stratified epithelial tissues and two control tissues, was analysed using principal components to cluster tissues based on gene expression profile similarity. Expression profiles of genes along the sheep GIT were used to generate a network to identify genes enriched for expression in different compartments of the GIT. The data from sheep was compared to similar data sets from two non-ruminants, pigs (closely related) and humans (more distantly related).

Results. The rumen transcriptome clustered with the skin and tonsil, but not the GIT transcriptomes, driven by genes from the epidermal differentiation complex, and genes encoding stratified epithelium keratins and innate immunity proteins. By analysing all of the gene expression profiles across tissues together 16 major clusters were identified. The strongest of these, and consistent with the high turnover rate of the GIT, showed a marked enrichment of cell cycle process genes $(P=1.4 \mathrm{E}-46)$, across the whole GIT, relative to liver and muscle, with

41 highest expression in the caecum followed by colon and rumen. The expression patterns of 42 several membrane transporters (chloride, zinc, nucleosides, amino acids, fatty acids, cholesterol 
43 and bile acids) along the GIT was very similar in sheep, pig and humans. In contrast, short chain

44 fatty acid uptake and metabolism appeared to be different between the species and different

45 between the rumen and colon in sheep. The importance of nitrogen and iodine recycling in sheep

46 was highlighted by the highly preferential expression of SLC14A1-urea (rumen), RHBG-

47 ammonia (intestines) and SLC5A5-iodine (abomasum). The gene encoding a poorly

48 characterized member of the maltase-glucoamylase family (MGAM2), predicted to play a role in

49 the degradation of starch or glycogen, was highly expressed in the small and large intestines.

50 Discussion. The rumen appears to be a specialised stratified cornified epithelium, probably

51 derived from the oesophagus, which has gained some liver-like and other specialized metabolic

52 functions, but probably not by expression of pre-existing colon metabolic programs. Changes in

53 gene transcription downstream of the rumen also appear have occurred as a consequence of the

54 evolution of the rumen and its effect on nutrient composition flowing down the GIT. 


\section{INTRODUCTION}

58 The ruminants, of which sheep, cattle, buffalo and goats are the major domesticated species,

59 are now the most numerous large herbivores on earth. Their success is largely due to their specialized forestomachs, the rumen complex (the rumen, reticulum and omasum), and to rumination, the process of recycling the partially digested material via the mouth to reduce particle size and increase rate of fermentation (Hofmann, 1989). The forestomachs follow the oesophagus and precede the abomasum (the equivalent of the stomach of non-ruminants) (Hofmann, 1989). The evolutionary origin of the rumen is the subject of debate with outpouching of the oesophagus, or of the stomach, as the most likely origins (Beck et al., 2009; Langer, 1988). The primary chambers of the rumen facilitate the action of a complex mixture of micro-organisms to ferment a portion of the plant polysaccharides (including starch, xylan and cellulose) and lipids to short chain volatile fatty acids (SCFAs), principally acetate, butyrate and propionate (Bergman, 1990). The SCFAs are the primary energy source in carbon of ruminants, and the rumen is the major site of their uptake.

From the rumen, partially processed plant material, nutrients, and micro-organisms pass through the omasum and enter the conventional gastrointestinal system: the abomasum, and the small and large intestines for further digestion and fermentation (in the large intestine). The abomasum is primarily a digestive organ lowering the $\mathrm{pH}$ of the rumen fluid and facilitating the first step of proteolysis prior to more extensive degradation in the duodenum and absorption of amino acids and small peptides. Pancreatic RNAses degrade microbial RNA in the small intestine contributing to nitrogen availability. On pasture, roughage or grass diets only small amounts of starch escape fermentation in the rumen and the remaining starch is generally digested in the small intestine, providing limited amounts of glucose (Deckardt et al., 2013). 
80

81

82

83

84

85

86

87

88

89

90

91

92

93

94

95

96

97

98

99

100

101

102

Depending on the dietary source larger amounts of starch may escape fermentation in the rumen (Huntington, 1997). As a consequence glucose is not a major source of carbon in ruminants, and the liver is not a major site of (fatty acids) FA synthesis (Ingle et al., 1972). Biohydrogenation processes in the rumen (Van Nevel \& Demeyer, 1996) increase the saturation of fatty acids (Jenkins et al., 2008; Van Nevel \& Demeyer, 1996), and lipids that escape fermentation in the rumen are taken up in the small intestine. Fermentation of the remaining carbohydrates, lipid etc. occurs in the large intestine/hindgut. The hindgut is responsible for 5-10\% of the total digestion of carbohydrates (Gressley et al., 2011) and for 8 to 17\% of total production of SCFAs (Hoover, 1978). This contribution of hindgut fermentation may be altered on high grain diets (Fox et al., 2007; Mbanzamihigo et al., 1996). The overlap in functions of the rumen and the hindgut raises the question of whether the equivalent processes in the two tissues are undertaken by the same proteins and pathways; that is co-option of the hindgut program by the rumen, or by different proteins and pathways resulting from convergent evolution.

Unlike the stomach and subsequent segments of the GIT the rumen surface is a stratified squamous epithelium that is cornified and keratinized to protect the rumen from physical damage from the ingested plant material (Scocco et al., 2013). Due to the large numbers of microorganisms in the rumen it is also exposed to colonization of surfaces and potential attack from these organisms. The nature of the defences and the interaction between the surface of the rumen and the microbial populations has not been investigated in detail.

Herein, we utilised the latest sheep genome and transcriptome data (Jiang et al., 2014) to further dissect gene expression features of the ruminant GIT. We analyze the transcriptomes of six GIT tissue/cell types covering the majority of the sheep GIT in the context of reference samples from two other tissues with stratified squamous epithelium (skin and tonsil), another 
103 component of the immune system (spleen), and two non-epithelial tissues (liver and muscle).

104 Further, we systematically compared our results with existing transcriptome data from the human

105 and pig gastrointestinal tracts and with relevant literature using candidate gene/protein based

106 approaches. Our major aims were to identify: i) the distinctive features of ruminant GIT, ii) the

107 common features shared between ruminant and mammalian GIT and iii) the developmental

108 origin of the rumen.

109 METHODS

\section{Data acquisition and statistical analysis}

111 No new primary datasets were generated in this work, the major secondary datasets are included

112 in the supplementary material. The sample preparation procedures and sequencing of the RNA

113 are described in (Jiang et al., 2014) and experimental animal information were specified in

114 Additional file 1: Table S1. Briefly, tissue samples were obtained from a trio of Texel sheep, i.e.,

115 ram (r), ewe (e) and their lamb (1). RNA was prepared and sequenced using stranded Illumina

116 RNA-Seq with a yield of 70-150 million reads per tissue sample. 26 files of RNA sequence

117 alignment data in the BAM format for 11 tissue/cell types, including skin $(n=3)$, tonsil $(n=1 r)$,

118 ventral rumen $(n=3)$, abomasum $(n=3)$, duodenum $(n=1 r)$, caecum $(n=2, r$ and 1$)$, colon $(n=3)$,

119 rectum $(n=3)$, spleen $(n=2, r$ and 1$)$, liver $(n=2, r$ and e) and muscle $(n=3)$, was downloaded from

120 the Ensembl sheep RNA sequencing archive, Oar_v3.1 (Huttenhower et al., 2009; Jiang et al.,

121 2014). Detailed animal and gender distribution can be found in Supplementary Figure S1.

122 Detailed raw RNA sequencing data from the same samples was also retrieved from the European

123 Nucleotide Archive (ENA), study accession PRJEB6169. The raw mapping counts for each gene

124 were calculated from the downloaded BAM files and the Ensembl sheep gene models (Ensembl),

125 with additional gene models for genes at the EDC locus not included in the Ensembl sheep gene 
126 models (Jiang et al., 2014), using HTSeq in the Python environment (Anders et al., 2015). The

127 raw count data was normalized and clustered with DEseq2 (Love et al., 2013) to produce PCA

128 plots and variance-stabilizing transformed gene expression values for network analysis described

129 below. DEseq2 produced PCA sample clustering was further tested for significance using a k-

130 means method and bivariate $\mathrm{t}$-distributions based on the eigenvalues of the principle

131 components. Calculation was performed using the stat_ellipse package (2012) and the raw

132 outputs were presented in ggplot2 in R. EdgeR (Robinson et al., 2010) in Bioconductor in R

$133 \mathrm{v} 3.1 .3$ was used to analysis gene differential expression. After filtering for transcripts with at

134 least 1 count per million in at least one of the 11 tissues, data was analysed using the Analysis of

135 Variance-like procedure (special feature in EdgeR) and fitted to a simple model:

$136 y=$ tissue $_{i}+$ animal $_{j}+e_{i j}$. Where $y$ is raw transcript counts, tissue $_{i}(i=11)$ is 11 types of tissues

137 and $\operatorname{animal}_{j}(j=3)$ is the adjustment of types of animal (lamb, ram and ewe). Transcripts with

138 significance levels $(P)<0.01$ and false discovery rate $(\mathrm{FDR})<0.01$ for tissue effects and

139 differentially expressed in at least one of the 11 tissues were identified.

\section{Co-expression network analysis}

141 Variance-stabilizing transformed RNA sequencing expression values have properties similar to

142 normalized microarray expression values in terms of network analysis (Giorgi et al., 2013) and

143 raw counts of differentially expressed $(\mathrm{FDR}<0.01)$ transcripts were variance-stabilizing

144 transformed (Durbin et al., 2002) using DEseq2. Transformed expression values were analyzed

145 for co-expression using PCIT (Hudson et al., 2012; Reverter \& Chan, 2008) in R v3.1.3

146 (Watson-Haigh et al., 2010). To reduce the complexity of the network the PCIT output was

147 filtered for pairs of genes with a correlation coefficient $>0.9$ and visualized in Cytoscape v3.1.2

148 (Shannon et al., 2003). The network cluster algorithm 'community cluster' within the GLay 
149 plugin (Su et al., 2010) of cytoscape was used to subdivide the large network and identify

150 explanatory sub-networks in an iterative manner until no obvious sub-network was observed in

151 the large network. Pig genes assigned to 10 clusters showing differential expression in the pig

152 GIT (Freeman et al., 2012) were mapped to sheep genes based on their gene symbols. The

153 probability of over or under representation of pig GIT genes in a sheep GIT gene cluster was

154 calculated using the hypergeometric distribution (Andrews et al., 1999). Functional enrichment

155 of shared sets of genes within sheep clusters was analyzed using GOrilla (Eden et al., 2009) to

156 identify biological pathways.

\section{Gene expression pattern clustering}

158 The transcripts present in the gene networks described above, and with an ANOVA $P<0.01$ and

159 a FDR $<0.01$, were included in $k$-mean clustering in $\mathrm{R} \mathrm{v3.1.3} \mathrm{based} \mathrm{on} \log _{2}$ fold change across

16011 tissues with abomasum being the reference. The k-mean analysis aimed to identify expression

161 patterns to represent transcript groups showing elevated expression levels for the following sets

162 of tissues v. the remaining tissues: 1) all GIT tissues, i.e., rumen, abomasum, duodenum,

163 caecum, colon and rectum, 2) rumen and abomasum, 3) rumen and intestinal tissues, 4)

164 abomasum and intestinal tissues, 5) rumen, 6) abomasum, 7) intestinal tissues, 8) rumen and

165 skin, 9) rumen and tonsil, 10) rumen, skin and tonsil, 11) spleen, duodenum, caecum, and colon.

166 The transcript names are determined based on the tissue(s) where included transcripts showed

167 the highest expression. We filtered these identified transcript clusters with the criteria that 1) the

168 average absolute expression of the transcript at the highest expressed tissue $>3$ count per

169 million, 2) the $\log _{2}$ expression fold difference of expression of the transcript from the tissue

170 within the reference tissue group with the highest expression to the tissue within the elevated

171 expressed tissue group with the highest expression, be $>0.5$, and 3) from the tissue with the 
172 highest expression to the tissue with the lowest expression within the elevated tissue group be $<$

173 0.5. The final expression of each transcript is presented in the format of $\log 2$ Fragments Per

174 Kilobase of exon per Million fragments mapped (FPKM). Selected gene members and associated

175 pathways were presented in heat maps based on their log2 FKPM values using GENE-E (Gould).

176 To understand the GIT associated SLC family genes, we performed a network analysis of

177 expression as above. The PCIT output of network matrix was filtered for correlation coefficient

$178>0.7$, clustered by GLay (Su et al., 2010) and visualized in Cytoscape v3.1.2 (Shannon et al., 179 2003).

\section{Comprehensive transcript annotation}

181 To complement the sheep genome annotation, we used multiple annotation sources and software

182 to identify the function of the products encoded by the identified transcripts. Firstly, the transcripts of interest, both with or without a gene symbol, were validated for existence on the

184 sheep genome, using comparisons of the sheep gene along within the locus with its ortholog(s) of

185 human and bovine from Ensembl and NCBI. Secondly, GO was used to annotate genes. Thirdly, 186 the functions and annotations of the genes were searched in Ensembl and NCBI, if no available 187 description or gene information were identified, the biomedical literature was searched with 188 GenCLiP 2.0 (Wang et al., 2014). When multiple biomedical functions were listed, functions 189 related to gastrointestinal activity were prioritized for annotation. Fourthly, for a subset of genes 190 Unigene (McGrath et al., 2010) and Genevestigator (Hruz et al., 2008) were used to identify 191 transcript expression patterns in cattle and humans respectively. Protein sequences analysis was 192 performed using Radar (Heger \& Holm, 2000), to identify amino acid sequence repeats, and 193 NetOGlyc 4.0 (Steentoft et al., 2013), to identify glycosylation sites. 


\section{Data access}

195 No new primary datasets were generated in this work, the major secondary datasets are included 196 in the supplementary material.

\section{RESULTS AND DISCUSSION}

199

200

201

202

203

204

205

206

207

208

209

210

211

212

213

214

215

216

\section{Clustering of sheep GIT tissue transcriptomes}

We performed principal component analysis (PCA) using RNA-Seq data from six GIT (rumen, abomasum, duodenum, caecum, colon and rectum), two epithelial (skin and tonsil), an immune (spleen) and two reference (liver and muscle) tissue/cell types from a trio of Texel sheep (ram, ewe and lamb (Jiang et al., 2014)). We included a total of 26 tissue samples, a similar tissue sample coverage to a previous transcriptomic study of the pig GIT (Freeman et al., 2012) to which the results of this analysis will be compared below. Three clusters of tissues were identified at the $95 \%$ confidence interval: cluster 1 , skin, tonsil and rumen, cluster 2 , muscle, and cluster 3, liver, spleen and the remaining GIT tissues (Figure 1A, Additional file: Figure S1A).

\section{Identification of common and specific GIT and epithelial transcriptomic signatures}

To identify the genes driving the clustering of the tissues we identified those transcripts with an ANOVA $P<0.01$ and a false discovery rate $(\mathrm{FDR})<0.01$, for differential expression in at least one tissue versus the other tissue types. This multi-tissue comparison reduced the impact of the small sample size for some tissues, in particular the duodenum (one tissue sample). Secondly, for a conservative gene network cluster analysis, the pair-wise gene correlation coefficient cut-off was set to 0.9 and we further filtered transcripts based on relative (fold change) and absolute (count per million) expression levels. We identified 16 major gene expression patterns, 
217 representing common and specific transcriptomic signatures of the epithelial and GI tissues,

218 accounting for 639 different transcripts (Figure 2A). A full list of the expression of the genes

219 across the tissues with assignment to clusters is available (Additional file 1: Table S2, S3). Gene

220 Ontology enrichment analysis of the clusters identified a number of significantly enriched terms

221 (Table 1). A full list of the genes contributing to the enrichments is available (Additional file 1:

222 Table S4). Most notable was the highly significant enrichment of the genes in the epithelia-

223 intestine cluster for the GO-term, "cell cycle process". The higher expression of the majority of

224 these genes in the epithelial and GIT tissues (Figure 2, Supplementary Table S2) is consistent

225 with the much higher turnover rate of these tissues compared to liver and muscle (Milo et al.,

226 2010) and may contribute to the structural adaptability of the rumen epithelia to different diets

227 and health conditions (Dionissopoulos et al., 2012; Penner et al., 2011). Epithelia structure

228 related pathways including 'cell junctions' showed significant enrichment in genes highly

229 expressed in the rumen and the large intestine (Table 1). Gene members involved in cell junction

230 functions have been reported to be important for the rumen epithelia to maintain $\mathrm{pH}$ homeostasis

231 (Dionissopoulos et al., 2012; Steele et al., 2011a). Two other very significant enrichments were

232 observed, "flavonoid biosynthetic process" in the rumen-intestine-liver cluster and "regulation of

233 chloride transport" in the large intestine cluster (Table 1). The mammalian Epidermal

234 Development Complex (EDC) locus is a cluster of up to 70 adjacent genes encoding proteins

235 with roles in the development and the structure of stratified epithelia (Kypriotou et al., 2012).

236 Although no significant enrichment of genes in the rumen cluster was identified by GO analysis

237 several genes in the EDC region were very significantly overrepresented in the cluster (Table 1).

238 This is consistent with our previous identification of several ruminant specific genes at the EDC

239 locus highly preferentially expressed in the rumen (Jiang et al., 2014). The genes in the epithelia- 
240 rumen-tonsil cluster were also very significantly enriched for EDC genes (Table 1). Thus the

241 clustering of the rumen with the skin and tonsil appears to have been driven by genes involved in

242 the development and structure of the stratified epithelium.

\section{The stratified squamous rumen epithelium expression signature}

245 The EDC locus genes are not the only genes encoding proteins involved in the synthesis of the 246 cornified surface of the rumen and we looked for additional genes involved in cornification

247 preferentially expressed in the rumen compared to skin and tonsil. The cross linking of the 248 proteins of the cornified surface is mediated by transglutaminases (TGMs) (Eckert et al., 2005).

249 Multiple TGMs are expressed in the rumen in this study, TGM1 and TGM3 appear to be the 250 major rumen transglutaminases, but are also highly expressed in the skin (Figure 3). Keratins are 251 major components of the cornified layers so we asked the question, are there keratin genes highly

252 preferentially expressed in the rumen? Although no $K R T$ genes showed expression as exclusive 253 to the rumen as some of the EDC locus genes in our data, KRT36 was grouped in the rumen 254 expression cluster (Figure 3, Additional file 1: Table S3, Additional file 2: Figure S2), with 255 significantly elevated expression in rumen, compared to the other studied tissues, and limited

256

257

258

259

260

261 locus genes. 
262 Kallikrein-related peptidases are involved in the turnover of the cornified layers of the stratified

263 epithelia, and deficiencies can lead to altered turnover of the surface layers of the epithelia

264 (Hovnanian, 2013). In our study, KLK12 is the only $K L K$ family member preferentially

265 expressed in the rumen (Figure 3, Additional file 1: Table S2). Members of the SPINK (serine

266 peptidase inhibitor, Kazal type) family are inhibitors of the KLK family peptidases (Hovnanian,

267 2013), SPINK5 is the only member of the family that is highly expressed in the rumen (Figure 3,

268 Additional file 1: Table S2) in our data, but is also highly expressed in the tonsil and skin.

269 KLK12 and SPINK5 may be involved in the regulation of the turnover and thickness of the

270 cornified surface of the rumen epithelium, but may not form a rumen specific system.

271 Rumen micro-organism interactions

272 The rumen is the site of frequent interaction between the host and very dense populations of

273 micro-organisms. In our study, $D U O X 2$ and $D U O X A 2$ encoding subunits of dual oxidase were

274 preferentially expressed in the rumen (Figure 3), while DUOX1 showed rumen-biased expression

275 (Figure 3) and DUOXA1 was highly expressed in all epithelia tissues (Figure 3). This

276 observation is in line with the findings in the pig where the highest expression of DUOXA1 and

277 DUOX1 was in the epithelial tissues. e.g., tongue and lower oesophagus (Freeman et al., 2012).

278 In humans, the $D U O X A 1$ and $D U O X 1$ genes are also most highly expressed in epithelia tissues

279 exposed to air, whilst $D U O X 2$ and $D U O X A 2$ are most highly expressed in a different set of

280 tissues including the GIT (Genevestigator (Hruz et al., 2008) analysis). Thus, our findings

281 suggest that the DUOX1s are active in general epithelial tissues, while DUOX2s are probably

282 active specifically in rumen to play a major role in controlling microbial colonization. Previously

283 in sheep, the highest expression levels of $D U O X 1$ and $D U O X 2$ were reported in the bladder and 
284 abomasum, respectively, but the rumen and epithelial tissues were not included in the tissues

285 surveyed (Lees et al., 2012).

$286 P I P$, encoding prolactin-induced protein (an aspartyl protease), was preferentially expressed in

287 the rumen (Figure 3). In humans, PIP is also highly expressed in epidermal (Genevestigator

288 (Hruz et al., 2008) analysis) and exocrine tissues, and in pigs in the salivary gland. Although PIP

289 has been reported to be involved in regulation of the cell cycle in human breast epithelial cells

290 (Cassoni et al., 1995; Naderi \& Vanneste, 2014), its expression pattern in sheep (not part of the

291 cell cycle cluster) is more consistent with a role in mucosal immunity (Hassan et al., 2009). Also

292 highly expressed in the rumen were members of the SERPINB family of peptidase inhibitors

293 (Figure 3), which are involved in the protection of epithelial surfaces in humans (Wang et al., 294 2012) and mice (Sivaprasad et al., 2011). EDC locus genes PGLYRP3 and PGLYRP4 encode 295 peptidoglycan recognition proteins in the N-acetylmuramoyl-L-alanine amidase 2 family, which

296 bind to the murein peptidoglycans of Gram-positive bacteria as part of the innate immune 297 system. Additional EDC locus genes, S100A8, S100A9 and S100A12 (calgranulins A, B and C), 298 encode key players in the innate immune function (Funk et al., 2015; Tong et al., 2014).

\section{Rumen steroid metabolism}

300 Amongst the genes preferentially expressed in the rumen (and often the liver) we identified a to 20-alpha-hydroxy-progesterone (PGF2 $\alpha$ ) (Penning, 1997), retinals to retinols and bioactivates and detoxifies a range of molecules (El-Kabbani et al., 2011). Intravenous injection of PGF2 $\alpha$ in goats has been shown to increase contraction of rumen smooth muscle, which leads to a reduction in the contraction rate of the rumen (van Miert \& van Duin, 1991; Veenendaal et al., 
307 et al., 2015). The exact role of AKR1C1 in the rumen is unknown,. In addition, the gene

308 encoding the related enzyme AKR1D1 (catalyzes the reduction of progesterone,

309 androstenedione, 17-alpha-hydroxyprogesterone and testosterone to 5-beta-reduced metabolites)

310 is highly expressed in the rumen and the liver and the gene encoding ARK1C4 in the rumen,

311 liver and duodenum (Figure 4). The products of these genes are also likely to be involved in the

312 metabolism of steroids in the rumen epithelium. In addition, we observed marked pathway

313 enrichment of flavonoid biosynthetic process due to the identification of five members of the

314 UDP-glucuronosyltransferase (UGT) gene family [29], with the highest expression levels in the 315 rumen and liver (Additional file 1: Table S2). Flavonoids are only produced by plants, but UGT

316 enzymes are highly active in mammals and catalyze the glucuronidation of a diverse chemical

317 base including steroids, bile acids and opioids [29]. The functions of the products of these genes

318 in the rumen require further investigation. However, results discussed here suggest important

319 interactions between the rumen wall and activity of steroids.

320

321 Comparison of the sheep and pig GIT transcriptomes

322 To compare the ruminant and a closely related non-ruminant mammal GIT transcriptomes (Jiang

323 et al., 2014), we mapped those transcripts previously reported to show specific expression

324 patterns in the pig GIT (Freeman et al., 2012) to the sheep gene network (Figure 2B). Pig is the

325 genomically closest non-ruminant to the ruminants (Groenen et al., 2012; Jiang et al., 2014) for

326 which sufficient GIT transcriptome data is available. The overall overlap of the 639 genes in the

327 sheep GIT network and the 2634 mappable pig GIT genes is 179, which is highly significant

328 (Table 2). The smaller number of genes showing differential expression in our study versus the

329 pig study is due to the application of stringent statistical filtering thresholds to minimize the 
330 impact of the small number of samples per tissue. However, the overlap of 627 genes between

331 the set of 2475 sheep genes identified using relaxed filtering criteria and the 2634 pig genes was

332 also highly significant $(\mathrm{P}<10 \mathrm{E}-20)$, supporting the robustness of the approach. The set of 179

333 overlapping genes was highly significantly enriched for the GO-term "cell cycle process" (Table

334 2). The overlap of genes between the pig intestine clusters and the sheep epithelia-intestine

335 cluster was highly significant and the overlap genes were again very highly significantly

336 enriched for the GO-term "cell cycle process" (Table 2). A full list of the genes in the overlap

337 and assignment to the pig and sheep gene clusters is available (Additional file 1: Table S5).

338 Furthermore, pig genes preferentially expressed in the tongue and oesophagus have a highly

339 significant overlap with sheep genes with high expression in the rumen and epithelial tissues

340 (Figure 2B), enriched for the GO-term "epidermis development" (Table 2). Our results

341 emphasises the contribution of cell cycle to the renewal of mammalian GIT epithelial surfaces

342 (Crosnier et al., 2006).

\section{Ruminant specific pathways for SCFA uptake and GIT metabolism?}

344 SCFAs are the major source of energy in ruminants, with the primary sources of SCFAs being

345 the rumen, and to a much lesser extent the large intestine. Carbonic anhydrases, which hydrate

$346 \mathrm{CO}_{2}$ to bicarbonate, are thought to play a significant role in the uptake of SCFAs by an

$347 \mathrm{SCFA} /$ bicarbonate antiporter, and by providing protons at the rumen epithelium to neutralize the

348 SCFAs and promote their diffusion into the ruminal epithelium (Bergman, 1990; Wang et al.,

349 1996). There are many members of the carbonic anhydrase gene family (Tashian, 1989), several

350 of which are expressed in mammalian gastrointestinal tissues (Freeman et al., 2012; Kivel et al.,

351 2005; Parkkila et al., 1994; Tashian, 1989). In ruminants, $C A 1$ has previously been reported to

352 encode a rumen specific carbonic anhydrase with low activities in the blood (unlike in other 
353 mammals) and in the large intestines (Carter, 1971). Consistent with this, compared to all of the

354 other tissues in our dataset, $C A 1$ is highly expressed in the rumen and, albeit with lower but

355 significant expression, in the large intestine (Figure 4). CA2 and CA7 appear to encode the major

356 carbonic anhydrases in the large intestines (Figure 4). In humans $C A 1, C A 2$ and $C A 7$ are highly

357 expressed in the colon (Genevestigator (Hruz et al., 2008) analysis). In contrast in pigs, whilst

$358 C A 2$ is highly expressed in the stomach, it is not highly expressed in the large intestine and CA1

359 and $C A 7$ were not reported to be differentially expressed across the GIT (Freeman et al., 2012).

360 The apical membrane SCFA/bicarbonate antiporter exchanges intracellular bicarbonate with

361 intra-ruminal SCFA and consistent with previous publications, SLC4A9, preferentially expressed

362 in the rumen in our dataset (Figure 4), encodes the most likely antiporter. The proposed

363 basolateral membrane SCFA/bicarbonate antiporter gene SLC16A1 (exchanges intracellular

364 SCFA with blood bicarbonate), which has highest expression in the rumen in our dataset,

365 followed by the colon and rectum, has a much more general expression across the tissues than

366 SLC4A9 (Figure 4). These expression patterns are consistent with previous findings in cattle

367 (Connor et al., 2010). SLC16A1 is also likely to be involved in the transport of ketone bodies

368 into the blood supply to the basolateral surface of the rumen epithelium (van Hasselt et al.,

369 2014).

$370 \mathrm{HCO}_{3}{ }^{-}$-independent apical uptake of acetate in the rumen has also been observed (Aschenbach et

371 al., 2009). However, the transporter has not been identified, with candidates proposed in the

372 SLC4A, SLC16A, SLC21A, SLC22A and SLC26A families (Aschenbach et al., 2009). Members

373 of the SLC21A and SLC22A families showed generally low expression in the rumen in our study

374 (Additional file 1: Table S2). In addition to SLC16A1 and SLC4A9 discussed above, SLC26A2

375 and SLC26A3 are highly expressed in the rumen in our dataset (Figure 4). Both genes encode 
376 apical anion exchangers confirming them as candidates for encoding the apical $\mathrm{HCO}_{3}^{-}$-

377 independent acetate uptake transporter. $\mathrm{SLC} 26 \mathrm{~A} 3$ is a $\mathrm{Cl}^{-} / \mathrm{HCO}_{3}{ }^{-}$exchanger (see fluid and

378 electrolyte balance section below) and therefore is unlikely to be an $\mathrm{HCO}_{3}{ }^{-}$-independent acetate

379 transporter. However, SLC26A2 is a $\mathrm{SO}_{4}{ }^{2-} / \mathrm{OH}^{-} / \mathrm{Cl}^{-}$exchanger (Ohana et al., 2012) and remains a

380 candidate for the proposed apical $\mathrm{HCO}_{3}{ }^{-}$-independent acetate transporter. $\mathrm{An}^{\mathrm{HCO}_{3}}{ }^{-}$-independent

381 basolateral maxi-anion channel for SCFA- efflux to blood has also been proposed without an

382 assigned transporter (Georgi et al., 2014). A survey of ABC (ATP-binding cassette) family

383 transporters identified $A B C C 3$ as the most preferentially expressed in the rumen in our dataset

384 and with the second highest expression in the large intestine (Figure 4). ABBC3 is an organic

385 anion transporter with a possible role in biliary transport and intestinal excretion (Rost et al.,

386 2002). Therefore, $A B C C 3$ may be involved in the efflux transport of SCFA- from the rumen

387 epithelium to blood.

388 In most mammals, including humans, the liver is the major site of the synthesis of ketone bodies

389 (acetoacetate and beta-hydroxybutyrate), but in ruminants the epithelium of the rumen is a major

390 site of de novo ketogenesis (Lane et al., 2002). HMGCS2 encodes an HMG-CoA synthase (3-

391 hydroxy-3-methylglutaryl-CoA Synthase 2) in the ketogenesis pathway (Figure 5). This gene is

392 significantly associated with bovine butyrate metabolism (Baldwin et al., 2012) and the encoded

393 enzyme was predicted to be the rate limiting enzyme in sheep ruminal ketone body synthesis

394 (Lane et al., 2002). As expected, in our data HMGCS2 is highly expressed in the rumen

395 compared to the other GIT tissues and the liver (Figure 4). ACADS, HMGCL and BHD1, which

396 encode other enzymes involved in the ketone body pathway (Figure 5), are also highly expressed

397 in the rumen relative to most of the other tissues studied (Figure 4). HMGCS1 and ACAT2 may

398 also contribute to the ketone body pathway in the rumen, but their highest expression levels are 
399 in the liver (Table S1). However, their expression in the rumen has been reported to actively

400 respond to different diets (Steele et al., 2011b) and acidosis conditions (Steele et al., 2012) in

401 cattle. Whilst $H M G C S 2$ is quite highly expressed in the colon, in contrast $A C A D S, H M G C L$ and

402 BHD1 are not highly expressed (Figure 4), consistent with the colon not being a major

403 contributor to ketone body synthesis. Genes encoding enzymes for other steps in the pathways

404 from acetate and butyrate to ketone bodies are much more generally expressed across the tissues, 405 although expression of ECHSI and $A C A T 1$ are significantly higher in the rumen than in other

406 GIT tissues (Figure 4). In humans, in addition to the liver, HMGCS2 also has high expression in 407 the intestine, including the jejunum and colon (Genevestigator (Hruz et al., 2008) analysis). In 408 contrast, the only enzyme in the pathway (Figure 4, 5) reported to be preferentially expressed in 409 the pig GIT was $B D H 1$, in the fundus of the stomach (Additional file 1: Table S5). Thus the 410 rumen, abomasum, duodenum, caecum, colon and rectum in sheep all appear to have subtly 411 different SCFA transport and metabolism systems, and in the equivalent compartments of the 412 GIT appear to be different between sheep, humans and pigs.

413 Long chain fatty acids (LCFAs) uptake, cholesterol homeostasis and bile acid recycling

414 Due to the activity of the microbial populations of the rumen and the production of SCFAs

415 ruminants have less reliance on dietary LCFAs than non-ruminants. Does this reduced

416 importance lead to detectable differences in the transcriptome? The small intestine is the

417 principal site of uptake of LCFA and cholesterol homeostasis, and consistent with this the genes

418 encoding the well characterized components of the intestinal fatty acid uptake (CD36,

$419 S L C 27 A 2 / 4 / 5$ and FABP2 (Wang et al., 2013)) and cholesterol homeostasis (NPC1L1 and $420 A B C G 5 / 8$ (Wang et al., 2013)) systems are expressed in the sheep small intestine (Figure 4), as

421 they are in humans and most are in the pig (Freeman et al., 2012). FABP2 and $A B C G 5$ are 
422 particularly preferentially expressed in the sheep small intestine relative to other GIT tissues

423 (Figure 4). However, it is thought that the major route of LCFA uptake at the apical membrane

424 of the GIT epithelium is by passive diffusion (Abumrad \& Davidson, 2012).

425 Bile acids secreted by the liver and stored in the gall bladder before being released into the small

426 intestine play a major role in the uptake of LCFAs. Bile acids are recycled in the intestine.

427 SLC10A2 in the apical membrane and SLC51A and SLC51B in the basolateral membrane are 428 proposed to constitute the uptake systems in the human small intestine (Ballatori et al., 2013).

$429 S L C 10 A 2$ is also preferentially expressed in the small intestines of the pig, but preferential 430 expression of $S L C 51 A / B$ has not been reported (Freeman et al., 2012). In sheep SLC10A2 is 431 preferentially expressed in the small intestine, albeit it a low level (Figure 4). Whilst $S L C 51 B$ is

432 highly expressed in the duodenum in sheep, the highest expression of the two subunits together 433 in sheep $(S L C 51 A / B)$ is in the caecum and the colon (Figure 4), where they are also expressed in 434 humans and mice (Genevestigator (Hruz et al., 2008) analysis). Although described as subunits 435 of a complex, SLC51A and SLC51B have also been reported to be regulated differently (Ballatori 436 et al., 2013), thus the balance between expression of SLC10A2 and SLC51A and SLC51B may 437 indicate differences in the bile acid uptake pathways in the duodenum, large intestines and liver 438 of sheep.

439 Overall despite the reduced importance of LCFAs sheep appear to have a very similar systems to 440 human and pigs for LCFA uptake and bile acid recycling.

\section{Saccharide metabolism}

442 Again as a consequence of the activity of the rumen microbes in mature ruminants the uptake of 443 dietary glucose may be less than $10 \%$ of glucose requirements (Young, 1977). The dietary 
444 glucose comes primarily from the degradation of polysaccharides, in particular in the small

445 intestine of starch that has escaped degradation by the rumen microbial population. The primary

446 source of alpha-amylase required to digest the long polymers is the pancreas, which was not

447 investigated in this study. Genes encoding three enzymes likely to contribute to the digestion of

448 starch and other alpha-glycans, MGAM (maltase-glucoamylase), MGAM2 (maltase-glucoamylase

449 2) and SI (sucrase-isomaltase) (Nichols et al., 2003), were preferentially expressed in the tissues

450 studied here. SI was preferentially expressed in the intestine-low in rectum gene cluster, MGAM2

451 was highly expressed in all intestinal tissues, while $M G A M$ was also preferentially expressed in

452 the intestine (primarily the duodenum), but at a much lower level (Figure 4). In humans

453 (Genevestigator (Hruz et al., 2008) analysis) and pigs (Freeman et al., 2012), both MGAM and SI

454 are preferentially expressed in the small intestine. Expression of the orthologues of MGAM2 has

455 not been reported in the GIT of humans (Genevestigator (Hruz et al., 2008) analysis) or

456 pigs(Freeman et al., 2012) .

457 The mammalian $M G A M$ and $M G A M 2$ genes appear to have arisen by tandem duplication of a

458 single ancestral gene at the base of the mammals (Nichols et al., 2003; Nichols et al., 1998).

459 MGAM2 genes are present in most mammals, but have been annotated as possible pseudogenes

460 in a number of species, including man (NCBI LOC93432). MGAM2 is not well characterized in

461 any species. Comparative analysis of the protein sequences of MGAM and MGAM2 showed that

462 MGAM2 has additional sequence at the carboxy-terminus comprised of multiple copies of a 40

463 amino acid repeat not present in MGAM (Figure 6). The repeat unit is enriched in serine and

464 threonine, with similar sequences in the predicted sheep, cattle, pig and to a much lesser extent

465 human proteins (Figure 6). The repeat unit of MGAM2 is predicted to be heavily glycosylated

466 (Steentoft et al., 2013) to form a mucin-like domain. As in the rumen the microbial population in 
467 the large intestine ferments plant material, contributing up to $10 \%$ of the total carbohydrate

468 fermentation and conversion to SCFAs in the ruminant GIT (Gressley et al., 2011). Whilst the

469 role MGAM2 is unclear it appears to represent a contribution from the host to the breakdown of

470 plant polysaccharides by the bacterial population in the large intestine. MGAM produces glucose

471 from maltose and MGAM2 may have a similar functionality, and therefore contribute to the

472 uptake of the scarce supply of glucose in ruminants. Alternatively the high expression of

473 MGAM2 and low expression of MGAM may reflect the reduced availability of glucose in the

474 rumen GIT. Further investigation of this gene and the activity and function of its encoded protein

475 will improve our understanding of carbohydrate metabolism in the large intestine of ruminants.

476 In humans the major uptake of glucose in the GIT occurs in the small intestine via SLC5A1 (aka

477 SGLT1) in the apical membrane, and SLC2A2 (aka GLUT2) in the basolateral membrane (Roder

478 et al., 2014). The expression pattern of these two genes in sheep (Figure 4) and pigs (Freeman et

479 al., 2012) is consistent with a similar process in all three species.

\section{Nitrogen acquisition and recycling}

481 A high level of nitrogen recycling in the GIT is a characteristic of ruminants. Urea is the major

482 input from the animal (primarily via the saliva and the rumen epithelium) and anabolic-N sources

483 (in the small intestine) and ammonia (in the rumen, small and large intestines) are the major

484 uptake molecules from the GIT (Lapierre \& Lobley, 2001). SLC14A1 (Figure 4), encoding

485 SLC14A1 which mediates the basolateral cell membrane transport of urea, a key process in

486 nitrogen secretion into the GIT (Abdoun et al., 2010), is highly preferentially expressed in the

487 rumen in our dataset (Figure 4). However, in cattle expression of SLC14A1 was not affected by

488 differences in dietary N (Rojen et al., 2011) and doubts remain about the role of SLC14A1 in

489 increasing rumen epithelial urea permeability at low dietary N. Urea is also thought to be 
490 released by the epithelium of the small and large intestines (Lapierre \& Lobley, 2001), but our 491 analysis did not identify a potential transporter.

492 Urea is converted to ammonia by microbial ureases and is used by rumen microorganisms to 493 synthesize microbial proteins $(75-85 \%$ of microbial $N)$ and nucleic acids $(15-25 \%$ of microbial 494 N) (Fujihara \& Shem, 2011) which are subsequently digested by the host in the intestines, thus 495 recovering the majority of the secreted nitrogen (Abdoun et al., 2006). Consistent with this, $496 S L C 3 A 1$ (neutral and basic amino acid transporter) in our study is preferentially expressed in the 497 duodenum (Figure 4), as is SLC28A2 (concentrative nucleoside transporter) the product of which 498 plays in an important role in intestinal nucleoside salvage and energy metabolism (Huber-Ruano 499 et al., 2010). Both genes were also highly expressed in the small intestine of pigs (Freeman et al., 500 2012) and humans (Genevestigator (Hruz et al., 2008) analysis). RHBG (SLC42A2), an ammonia 501 transporter, is preferentially expressed in the sheep small and large intestines and the liver 502 (Figure 4) and is a candidate for an intestinal ammonia transporter. However, $R H B G$ is not 503 expressed at particularly high levels in the human GIT (Genevestigator (Hruz et al., 2008) analysis) relative to many other tissues, and was not reported to be preferentially expressed in the 505 pig GIT (Freeman et al., 2012). In humans uptake of ammonia in the large intestine is thought to 506 most likely occur (mainly) by passive non-ionic diffusion (Wrong \& Vince, 1984). However, 507 RHCG (apical membrane) and $R H B G$ (basolateral membrane) have also been proposed to 508 constitute an ammonium uptake pathway in the human GIT (Handlogten et al., 2005). The 509 expression profile of $R H C G$ in sheep (Figure 4) is not consistent with such a pathway in sheep.

510 In addition to the secretion of urea into the rumen (a ruminant specific process) the increased 511 importance of nitrogen recycling in ruminants may have led to the apparent increased expression 512 of $R H B G$ in the GIT of sheep. 


\section{Iodine recycling}

$514 S L C 5 A 5$, member 5 of solute carrier family 5, encoding a sodium iodide symporter is highly

515 preferentially expressed in the abomasum in our study (Figure 4). SLC5A5 also has higher

516 expression in human (Genevestigator (Hruz et al. 2008) analysis) and rat stomach (Kotani et al.,

517 1998) than in other digestive tissues. The latter authors reported that the distribution of SLC5A5

518 transcripts in the stomach epithelium was consistent with a role of SLC5A5 in the import or

519 export of iodine, from or to the stomach contents. In the rat, iodine is actively transported into

520 the gastric lumen and this transport is at least partly mediated by a sodium-iodide symporter

521 (Josefsson et al., 2006). In cattle the rate of iodine export by the abomasum epithelium into the

522 abomasum is much greater than the import of iodine from the abomasum (Miller et al., 1975),

523 suggesting that the role of SLC5A5 in sheep abomasum is to export iodine into the stomach

524 contents. In contrast, SLC5A5 was not reported to be significantly more expressed in the pig

525 stomach versus other components of the GIT (Freeman et al., 2012). The specific physiological

526 role of iodine in the stomach/GIT is unknown, but a number of possibilities have been suggested:

527 iodine-conserving mechanisms to deal with low iodine concentrations in the diet (Miller et al.,

528 1975), antioxidative activity (Venturi \& Venturi, 1999) and antimicrobial activity (Spitzweg et

529 al., 1999). The majority of the secreted iodine is thought to be recovered in the lower intestines.

530 Another member from the same transporter family SLC5A6, a sodium/multivitamin and iodide

531 co-transporter (de Carvalho \& Quick, 2011), encoded by a gene showing expression in all

532 studied tissues, with the highest expression sheep large intestine (Figure 4) is a likely candidate

533 for the iodine importer. In humans, SLC5A6 is also expressed in a wide range of tissues with

534 intestinal tissues being close to the top of the list (de Carvalho \& Quick, 2011). In pigs, SLC5A6

535 is preferentially expressed in the small intestine (Freeman et al., 2012). The high expression of 
536 SLC5A5 in the abomasum suggests that ruminants may have retained a higher dependence on

537 iodine in the GIT than other mammals.

\section{Zinc homeostasis}

$539 S L C 39 A 4$ encodes a transporter protein essential for zinc uptake in the mouse intestine (Dufner-

540 Beattie et al., 2003) and stomach (Martin et al., 2013). SLC39A4 is highly expressed in stomach

541 and intestines in sheep (Figure 4) and humans (Genevestigator (Hruz et al., 2008) analysis), and

542 showed the highest expression in pig small intestine (Freeman et al., 2012). Another zinc

543 transporter encoding gene, SLC39A5, has a similar expression profile to SLC39A4 in sheep

544 (Figure 4), humans and pigs. However, SLC39A5 is located in the basolateral membrane and is

545 involved in the secretion of zinc. In mouse gastrointestinal tract cells the two zinc transporters

546 are reciprocally regulated (Weaver et al., 2007), together controlling the influx and efflux of zinc

547 at the intestinal epithelium. It appears likely that sheep have a similar mechanism for zinc

548 homeostasis to other mammals.

\section{Fluid and electrolyte balance}

550 Maintaining salt and water balance is an important function of the mammalian GIT. In the large

551 intestine significant GO term enrichment was identified for regulation of chloride transport, due

552 to the inclusion of $C A 2,7$ and $C F T R$ (Table 1, Figure 4). This is in agreement with the reported

553 critical chloride secretory mechanism in intestinal epithelial cells, associated with mucosal

554 hydration (Barrett \& Keely, 2000). SLC26A3, which is a $\mathrm{Cl}^{-} / \mathrm{HCO}_{3}{ }^{-}$antiporter, imports $\mathrm{Cl}^{-}$ions

555 driven by bicarbonate, thus linking the activity of carbonic anhydrases and the leakage of $\mathrm{Cl}^{-}$out

556 of the cells by CFTR. SLC26A3 is preferentially expressed in the large intestine of sheep (Figure 
557 4) and the colon of pigs. Thus the expression of genes involved in fluid and electrolyte balance is

558 similar between all three species.

\section{Conclusions}

560 As a significant event in the evolution of the true ruminants, the evolutionary origin of the rumen

561 is the subject of debate, with out-pouching of the oesophagus, or of the stomach, as the two most

562 likely origins (Beck et al., 2009; Langer, 1988). The cornification of the epithelia surface, tissue

563 clustering analysis based on gene expression (driven by the epidermal structural proteins and

564 innate immunity genes) and the relative lack of metabolic overlap with the abomasum strongly

565 favours an oesophageal origin. Metabolically the rumen has many similarities with the liver,

566 especially for SCFA metabolism and even though there are functional similarities with the large

567 intestine, the complements of genes involved are not highly similar.

568 We have identified a small number of highly rumen specific metabolic processes, in particular

569 the roles of SLC14A1 (urea secretion), SLC4A9 (SCFA uptake) and AKR1C1 (uncertain

570 function). Overall our analysis has enabled gene expression data to be married up with decades

571 of physiological and other research to link transport and enzymatic activities and the most likely

572 genes encoding products with the activities. Nitrogen and iodine recycling have been identified

573 as processes with a much greater importance in the sheep than in humans or pigs. These

574 metabolic functions are protected by strong immune functions and stratified epidermis-like

575 epithelium. The major rumen immune players are DUOX and SERPINB gene families and

576 DUOXA2, DUOX2s and SERPINB3/4-like 1 appear to be preferentially expressed in the rumen.

577 These findings will bring novel insights into biomedical research on mammalian digestive and

578 gastrointestinal systems. 


\section{Additional files}

581

582

583

584

585

586

587

588

589

590

591

592

593

594

595

596

597

598

599

600

601

Additional file 1: Table S1. Sheep experimental design information. Table S2. Gene expression values with $P$ and FDR $<0.01$ across tissues. Table S3. Assignment of genes to tissue clusters.

Table S4. Gene members in each significant GO Term enrichment. Table S5. Genes overlapped between sheep and pig GIT clusters.

Additional file 2: Figure S1. Raw output of PCA clustering of tissues. Figure S2. Expression profile of GIT-related keratin genes. Figure S3. Clustering of transporter genes.

\section{Abbreviations}

\section{GIT: gastrointestinal tissue}

\section{Acknowledgements}

We would like to thank Richard Talbot for supervision of the generation of the RNA-Seq data.

\section{References}

2012. stat_ellipse https://github.com/JoFrhwld/FAAV/blob/master/r/stat-ellipse.R ) (accessed 03072015.

Abdoun K, Stumpff F, and Martens H. 2006. Ammonia and urea transport across the rumen epithelium: a review. Animal Health Research Reviews 7:43-59. $10.1017 / \mathrm{s} 1466252307001156$

Abdoun K, Stumpff F, Rabbani I, and Martens H. 2010. Modulation of urea transport across sheep rumen epithelium in vitro by SCFA and CO2. Am J Physiol Gastrointest Liver Physiol 298:G190-G202. 10.1152/ajpgi.00216.2009 
602

603

604

605

606

607

608

609

610

611

612

613

614

615

616

617

618

619

620

621

622

623

624

625

626

627

628

629

630

631

632

633

634

635

636

637

638

639

640

641

642

643

644

645

646

647

Abumrad NA, and Davidson NO. 2012. Role of the gut in lipid homeostasis. Physiological Reviews 92:1061-1085. 10.1152/physrev.00019.2011

Anders S, Pyl PT, and Huber W. 2015. HTSeq--a Python framework to work with highthroughput sequencing data. Bioinformatics 31:166-169. 10.1093/bioinformatics/btu638

Andrews GE, Askey R, and Roy R. 1999. Special functions - Encyclopedia of Mathematics. Cambridge: Cambridge University Press.

Aschenbach JR, Bilk S, Tadesse G, Stumpff F, and Gabel G. 2009. Bicarbonate-dependent and bicarbonate-independent mechanisms contribute to nondiffusive uptake of acetate in the ruminal epithelium of sheep. American Journal of Physiology Gastrointestinal and Liver Physiology 296:G1098-1107. 10.1152/ajpgi.90442.2008

Baldwin RLt, Wu S, Li W, Li C, Bequette BJ, and Li RW. 2012. Quantification of Transcriptome Responses of the Rumen Epithelium to Butyrate Infusion using RNA-seq Technology. Gene Regulation and Systems Biology 6:67-80. 10.4137/grsb.s9687

Ballatori N, Christian WV, Wheeler SG, and Hammond CL. 2013. The heteromeric organic solute transporter, OSTalpha-OSTbeta/SLC51: a transporter for steroid-derived molecules. Molecular Aspects of Medicine 34:683-692. 10.1016/j.mam.2012.11.005

Barrett KE, and Keely SJ. 2000. Chloride secretion by the intestinal epithelium: molecular basis and regulatory aspects. Annual Review of Physiology 62:535-572. 10.1146/annurev.physiol.62.1.535

Beck DC, Jiang H, and Zhang L. 2009. Elucidating the Evolutionary Relationships among Bos taurus Digestive Organs Using Unigene Expression Data. International Journal of Evolutionary Biology:Article ID 803142. 10.4061/2009/803142

Bergman EN. 1990. Energy contributions of volatile fatty acids from the gastrointestinal tract in various species. Physiological Reviews 70:567-590.

Carter MJ. 1971. The carbonic anhydrase in the rumen epithelial tissue of the ox. Biochimica et Biophysica Acta 235:222-236.

Cassoni P, Sapino A, Haagensen DE, Naldoni C, and Bussolati G. 1995. Mitogenic effect of the $15-\mathrm{kDa}$ gross cystic disease fluid protein (GCDFP-15) on breast-cancer cell lines and on immortal mammary cells. International Journal of Cancer 60:216-220.

Connor EE, Li RW, Baldwin RL, and Li C. 2010. Gene expression in the digestive tissues of ruminants and their relationships with feeding and digestive processes. animal 4:993-1007. $10.1017 / \mathrm{s} 1751731109991285$

Crosnier C, Stamataki D, and Lewis J. 2006. Organizing cell renewal in the intestine: stem cells, signals and combinatorial control. Nature Reviews Genetics 7:349-359. 10.1038/nrg1840

de Carvalho FD, and Quick M. 2011. Surprising substrate versatility in SLC5A6: $\mathrm{Na}^{+}$-coupled I ${ }^{-}$ transport by the human $\mathrm{Na}^{+}$/multivitamin transporter (hsmvt). Journal of Biological Chemistry 286:131-137. 10.1074/jbc.M110.167197

Deckardt K, Khol-Parisini A, and Zebeli Q. 2013. Peculiarities of enhancing resistant starch in ruminants using chemical methods: opportunities and challenges. Nutrients 5:1970-1988. 10.3390/nu5061970

Dionissopoulos L, Steele M, AlZahal O, and McBride B. 2012. Adaptation to high grain diets proceeds through minimal immune system stimulation and differences in extracellular matrix protein expression in a model of subacute ruminal acidosis in nonlactating dairy cows. American Journal of Animal and Veterinary Sciences 7:84-91.

Dufner-Beattie J, Wang F, Kuo Y-M, Gitschier J, Eide D, and Andrews GK. 2003. The Acrodermatitis Enteropathica Gene ZIP4 Encodes a Tissue-specific, Zinc-regulated Zinc 
648

Transporter in Mice. Journal of Biological Chemistry 278:33474-33481. 10.1074/jbc.M305000200

Durbin BP, Hardin JS, Hawkins DM, and Rocke DM. 2002. A variance-stabilizing transformation for gene-expression microarray data. Bioinformatics 18:S105-S110. 10.1093/bioinformatics/18.suppl_1.S105

Eckert RL, Sturniolo MT, Broome A-M, Ruse M, and Rorke EA. 2005. Transglutaminase Function in Epidermis. J Investig Dermatol 124:481-492.

Eden E, Navon R, Steinfeld I, Lipson D, and Yakhini Z. 2009. GOrilla: a tool for discovery and visualization of enriched GO terms in ranked gene lists. BMC Bioinformatics 10:48. 10.1186/1471-2105-10-48

El-Kabbani O, Dhagat U, and Hara A. 2011. Inhibitors of human 20alpha-hydroxysteroid dehydrogenase (AKR1C1). Journal of Steroid Biochemistry and Molecular Biology 125:105-111. 10.1016/j.jsbmb.2010.10.006

Ensembl. Sheep Genome v3.1 http://www.ensembl.org/Ovis aries/Info/Index (accessed 03072015.

Fox JT, Depenbusch BE, Drouillard JS, and Nagaraja TG. 2007. Dry-rolled or steam-flaked grain-based diets and fecal shedding of Escherichia coli O157 in feedlot cattle. Journal of Animal Science 85:1207-1212. 10.2527/jas.2006-079

Freeman T, Ivens A, Baillie JK, Beraldi D, Barnett M, Dorward D, Downing A, Fairbairn L, Kapetanovic R, Raza S, Tomoiu A, Alberio R, Wu C, Su A, Summers K, Tuggle C, Archibald A, and Hume D. 2012. A gene expression atlas of the domestic pig. BMC Biology 10:90.

Fujihara T, and Shem MN. 2011. Metabolism of microbial nitrogen in ruminants with special reference to nucleic acids. Animal Science Journal 82:198-208. 10.1111/j.17400929.2010.00871.x

Funk S, Mark R, Bayo P, Flechtenmacher C, Grabe N, Angel P, Plinkert PK, and Hess J. 2015. High S100A8 and S100A12 protein expression is a favorable prognostic factor for survival of oropharyngeal squamous cell carcinoma. International Journal of Cancer 136:20372046. $10.1002 / \mathrm{ijc} .29262$

Georgi MI, Rosendahl J, Ernst F, Gunzel D, Aschenbach JR, Martens H, and Stumpff F. 2014. Epithelia of the ovine and bovine forestomach express basolateral maxi-anion channels permeable to the anions of short-chain fatty acids. Pflügers Archiv European Journal of Physiology 466:1689-1712. 10.1007/s00424-013-1386-x

Giorgi FM, Del Fabbro C, and Licausi F. 2013. Comparative study of RNA-seq- and Microarrayderived coexpression networks in Arabidopsis thaliana. Bioinformatics 29:717-724. 10.1093/bioinformatics/btt053

Gould J. http://www.broadinstitute.org/cancer/software/GENE-E/2015).

Gressley TF, Hall MB, and Armentano LE. 2011. Ruminant Nutrition Symposium: Productivity, digestion, and health responses to hindgut acidosis in ruminants. Journal of Animal Science 89:1120-1130. 10.2527/jas.2010-3460

Groenen MAM, Archibald AL, Uenishi H, Tuggle CK, Takeuchi Y, Rothschild MF, RogelGaillard C, Park C, Milan D, Megens H-J, Li S, Larkin DM, Kim H, Frantz LAF, Caccamo M, Ahn H, Aken BL, Anselmo A, Anthon C, Auvil L, Badaoui B, Beattie CW, Bendixen C, Berman D, Blecha F, Blomberg J, Bolund L, Bosse M, Botti S, Bujie Z, Bystrom M, Capitanu B, Carvalho-Silva D, Chardon P, Chen C, Cheng R, Choi S-H, Chow W, Clark RC, Clee C, Crooijmans RPMA, Dawson HD, Dehais P, De Sapio F, Dibbits B, Drou N, Du 
694

695

696

697

698

699

700

701

702

703

704

705

706

707

708

709

710

711

712

713

714

715

716

717

718

719

720

721

722

723

724

725

726

727

728

729

730

731

732

733

734

735

736

737
Z-Q, Eversole K, Fadista J, Fairley S, Faraut T, Faulkner GJ, Fowler KE, Fredholm M, Fritz E, Gilbert JGR, Giuffra E, Gorodkin J, Griffin DK, Harrow JL, Hayward A, Howe K, Hu ZL, Humphray SJ, Hunt T, Hornshoj H, Jeon J-T, Jern P, Jones M, Jurka J, Kanamori H, Kapetanovic R, Kim J, Kim J-H, Kim K-W, Kim T-H, Larson G, Lee K, Lee K-T, Leggett R, Lewin HA, Li Y, Liu W, Loveland JE, Lu Y, Lunney JK, Ma J, Madsen O, Mann K, Matthews L, McLaren S, Morozumi T, Murtaugh MP, Narayan J, Truong Nguyen D, Ni P, Oh S-J, Onteru S, Panitz F, Park E-W, Park H-S, Pascal G, Paudel Y, Perez-Enciso M, Ramirez-Gonzalez R, Reecy JM, Rodriguez-Zas S, Rohrer GA, Rund L, Sang Y, Schachtschneider K, Schraiber JG, Schwartz J, Scobie L, Scott C, Searle S, Servin B, Southey BR, Sperber G, Stadler P, Sweedler JV, Tafer H, Thomsen B, Wali R, Wang J, Wang J, White S, Xu X, Yerle M, Zhang G, Zhang J, Zhang J, Zhao S, Rogers J, Churcher C, and Schook LB. 2012. Analyses of pig genomes provide insight into porcine demography and evolution. Nature 491:393-398.

http://www.nature.com/nature/journal/v491/n7424/abs/nature11622.html\#supplementaryinformation

Handlogten ME, Hong SP, Zhang L, Vander AW, Steinbaum ML, Campbell-Thompson M, and Weiner ID. 2005. Expression of the ammonia transporter proteins Rh B glycoprotein and Rh C glycoprotein in the intestinal tract. American Journal of Physiology Gastrointestinal and Liver Physiology 288:G1036-1047. 10.1152/ajpgi.00418.2004

Hassan MI, Waheed A, Yadav S, Singh TP, and Ahmad F. 2009. Prolactin inducible protein in cancer, fertility and immunoregulation: structure, function and its clinical implications. Cellular and Molecular Life Sciences 66:447-459. 10.1007/s00018-008-8463-x

Heger A, and Holm L. 2000. Rapid automatic detection and alignment of repeats in protein sequences. Proteins 41:224-237.

Hofmann R. 1989. Evolutionary steps of ecophysiological adaptation and diversification of ruminants: a comparative view of their digestive system. Oecologia 78:443-457.

Hoover WH. 1978. Digestion and absorption in the hindgut of ruminants. Journal of Animal Science 46:1789-1799.

Hovnanian A. 2013. Netherton syndrome: skin inflammation and allergy by loss of protease inhibition. Cell \& Tissue Research 351:289-300. 10.1007/s00441-013-1558-1

Hruz T, Laule O, Szabo G, Wessendorp F, Bleuler S, Oertle L, Widmayer P, Gruissem W, and Zimmermann P. 2008. Genevestigator v3: a reference expression database for the metaanalysis of transcriptomes. Adv Bioinformatics 2008:420747. 10.1155/2008/420747

Huber-Ruano I, Pinilla-Macua I, Torres G, Casado FJ, and Pastor-Anglada M. 2010. Link between high-affinity adenosine concentrative nucleoside transporter-2 (CNT2) and energy metabolism in intestinal and liver parenchymal cells. Journal of Cellular Physiology 225:620-630. 10.1002/jcp.22254

Hudson N, Dalrymple B, and Reverter A. 2012. Beyond differential expression: the quest for causal mutations and effector molecules. BMC Genomics 13:356.

Huttenhower C, Haley EM, Hibbs MA, Dumeaux V, Barrett DR, Coller HA, and Troyanskaya OG. 2009. Exploring the human genome with functional maps. Genome Research 19:10931106. 10.1101/gr.082214.108

Ingle DL, Bauman DE, and Garrigus US. 1972. Lipogenesis in the Ruminant: in vivo Site of Fatty Acid Synthesis in Sheep. Journal of Nutrition 102:617-623. 
738

739

740

741

742

743

744

745

746

747

748

749

750

751

752

753

754

755

756

757

758

759

760

761

762

763

764

765

766

767

768

769

770

771

772

773

774

775

776

777

778

779

780

781
Jenkins TC, Wallace RJ, Moate PJ, and Mosley EE. 2008. Recent advances in biohydrogenation of unsaturated fatty acids within the rumen microbial ecosystem. Journal of Animal Science 86:397-412. 10.2527/jas.2007-0588

Jiang Y, Xie M, Chen W, Talbot R, Maddox JF, Faraut T, Wu C, Muzny DM, Li Y, Zhang W, Stanton J-A, Brauning R, Barris WC, Hourlier T, Aken BL, Searle SMJ, Adelson DL, Bian C, Cam GR, Chen Y, Cheng S, DeSilva U, Dixen K, Dong Y, Fan G, Franklin IR, Fu S, Fuentes-Utrilla P, Guan R, Highland MA, Holder ME, Huang G, Ingham AB, Jhangiani SN, Kalra D, Kovar CL, Lee SL, Liu W, Liu X, Lu C, Lv T, Mathew T, McWilliam S, Menzies M, Pan S, Robelin D, Servin B, Townley D, Wang W, Wei B, White SN, Yang X, Ye C, Yue Y, Zeng P, Zhou Q, Hansen JB, Kristiansen K, Gibbs RA, Flicek P, Warkup CC, Jones HE, Oddy VH, Nicholas FW, McEwan JC, Kijas JW, Wang J, Worley KC, Archibald AL, Cockett N, Xu X, Wang W, and Dalrymple BP. 2014. The sheep genome illuminates biology of the rumen and lipid metabolism. Science 344:1168-1173. 10.1126/science. 1252806

Josefsson M, Evilevitch L, Westrom B, Grunditz T, and Ekblad E. 2006. Sodium-iodide symporter mediates iodide secretion in rat gastric mucosa in vitro. Experimental Biology and Medicine (Maywood, NJ) 231:277-281.

Kato D, Suzuki Y, Haga S, So K, Yamauchi E, Nakano M, Ishizaki H, Choi K, Katoh K, and Roh S-G. 2015. Utilization of digital differential display to identify differentially expressed genes related to rumen development. Animal Science Journal:n/a-n/a. 10.1111/asj.12448

Kivel AJ, Kivel J, Saarnio J, and Parkkila S. 2005. Carbonic anhydrases in normal gastrointestinal tract and gastrointestinal tumours. World Journal of Gastroenterology 11:155-163.

Kotani T, Ogata Y, Yamamoto I, Aratake Y, Kawano JI, Suganuma T, and Ohtaki S. 1998. Characterization of gastric Na+/I- symporter of the rat. Clinical Immunology and Immunopathology 89:271-278.

Kypriotou M, Huber M, and Hohl D. 2012. The human epidermal differentiation complex: cornified envelope precursors, S100 proteins and the 'fused genes' family. Experimental Dermatology 21:643-649. 10.1111/j.1600-0625.2012.01472.x

Lane MA, Baldwin RLt, and Jesse BW. 2002. Developmental changes in ketogenic enzyme gene expression during sheep rumen development. Journal of Animal Science 80:1538-1544.

Langer P. 1988. The mammalian herbivore stomach: comparative anatomy, function and evolution: Gustav Fischer.

Lapierre H, and Lobley GE. 2001. Nitrogen Recycling in the Ruminant: A Review. Journal of Dairy Science 84:E223-E236. 10.3168/jds.S0022-0302(01)70222-6

Lees MS, H. Nagaraj S, Piedrafita DM, Kotze AC, and Ingham AB. 2012. Molecular cloning and characterisation of ovine dual oxidase 2. Gene 500:40-46.

Li Y, Carrillo JA, Ding Y, He Y, Zhao C, Zan L, and Song J. 2015. Ruminal Transcriptomic Analysis of Grass-Fed and Grain-Fed Angus Beef Cattle. PLOS ONE 10:e0116437. 10.1371/journal.pone.0116437

Love M, Anders S, and Huber W. 2013. Differential analysis of count data-the DESeq2 package. Martin AB, Aydemir TB, Guthrie GJ, Samuelson DA, Chang SM, and Cousins RJ. 2013. Gastric and colonic zinc transporter ZIP11 (SLC39A11) in mice responds to dietary zinc and exhibits nuclear localization. Journal of Nutrition 143:1882-1888. 10.3945/jn.113.184457 
782

783

784

785

786

787

788

789

790

791

792

793

794

795

796

797

798

799

800

801

802

803

804

805

806

807

808

809

810

811

812

813

814

815

816

817

818

819

820

821

822

823

824

825

Mbanzamihigo L, van Nevel CJ, and Demeyer DI. 1996. Lasting effects of monensin on rumen and caecal fermentation in sheep fed a high grain diet. Animal Feed Science and Technology 62:215-228.

McGrath JA, Bolling MC, and Jonkman MF. 2010. Lethal Acantholytic Epidermolysis Bullosa. Dermatologic Clinics 28:131-135.

Miller JK, Swanson EW, and Spalding GE. 1975. Iodine Absorption, Excretion, Recycling, and Tissue Distribution in the Dairy Cow. Journal of Dairy Science 58:1578-1593. 10.3168/jds.S0022-0302(75)84753-9

Milo R, Jorgensen P, Moran U, Weber G, and Springer M. 2010. BioNumbers--the database of key numbers in molecular and cell biology. Nucleic Acids Research 38:D750-753. 10.1093/nar/gkp889

Naderi A, and Vanneste M. 2014. Prolactin-induced protein is required for cell cycle progression in breast cancer. Neoplasia 16:329-342 e321-314. 10.1016/j.neo.2014.04.001

Nichols BL, Avery S, Sen P, Swallow DM, Hahn D, and Sterchi E. 2003. The maltaseglucoamylase gene: common ancestry to sucrase-isomaltase with complementary starch digestion activities. Proc Natl Acad Sci U S A 100:1432-1437. 10.1073/pnas.0237170100

Nichols BL, Eldering J, Avery S, Hahn D, Quaroni A, and Sterchi E. 1998. Human small intestinal maltase-glucoamylase cDNA cloning. Homology to sucrase-isomaltase. Journal of Biological Chemistry 273:3076-3081.

Ohana E, Shcheynikov N, Park M, and Muallem S. 2012. Solute carrier family 26 member a2 (SLC26A2) protein functions as an electroneutral SOFormula/OH-/Cl- exchanger regulated by extracellular Cl. Journal of Biological Chemistry 287:5122-5132. 10.1074/jbc.M111.297192

Parkkila S, Parkkila AK, Juvonen T, and Rajaniemi H. 1994. Distribution of the carbonic anhydrase isoenzymes I, II, and VI in the human alimentary tract. Gut 35:646-650. 10.1136/gut.35.5.646

Penner GB, Steele MA, Aschenbach JR, and McBride BW. 2011. Ruminant Nutrition Symposium: Molecular adaptation of ruminal epithelia to highly fermentable diets. Journal of Animal Science 89:1108-1119. 10.2527/jas.2010-3378

Penning TM. 1997. Molecular endocrinology of hydroxysteroid dehydrogenases. Endocrine Reviews 18:281-305. 10.1210/edrv.18.3.0302

Reverter A, and Chan EKF. 2008. Combining partial correlation and an information theory approach to the reversed engineering of gene co-expression networks. Bioinformatics 24:2491-2497. 10.1093/bioinformatics/btn482

Robinson MD, McCarthy DJ, and Smyth GK. 2010. edgeR: a Bioconductor package for differential expression analysis of digital gene expression data. Bioinformatics 26:139-140. 10.1093/bioinformatics/btp616

Roder PV, Geillinger KE, Zietek TS, Thorens B, Koepsell H, and Daniel H. 2014. The role of SGLT1 and GLUT2 in intestinal glucose transport and sensing. PLoS ONE 9:e89977. 10.1371/journal.pone.0089977

Rojen BA, Poulsen SB, Theil PK, Fenton RA, and Kristensen NB. 2011. Short communication: Effects of dietary nitrogen concentration on messenger RNA expression and protein abundance of urea transporter-B and aquaporins in ruminal papillae from lactating Holstein cows. Journal of Dairy Science 94:2587-2591. 10.3168/jds.2010-4073 
826

827

828

829

830

831

832

833

834

835

836

837

838

839

840

841

842

843

844

845

846

847

848

849

850

851

852

853

854

855

856

857

858

859

860

861

862

863

864

865

866

867

868

869

870

Rost D, Mahner S, Sugiyama Y, and Stremmel W. 2002. Expression and localization of the multidrug resistance-associated protein 3 in rat small and large intestine. Am J Physiol Gastrointest Liver Physiol 282:G720-G726. 10.1152/ajpgi.00318.2001

Scocco P, Mercati F, Brusaferro A, Ceccarelli P, Belardinelli C, and Malfatti A. 2013. Keratinisation degree of rumen epithelium and body condition score in sheep grazing on Brachypodium rupestre. Veterinaria Italiana 49:211-217.

Shannon P, Markiel A, Ozier O, Baliga NS, Wang JT, Ramage D, Amin N, Schwikowski B, and Ideker T. 2003. Cytoscape: a software environment for integrated models of biomolecular interaction networks. Genome Research 13:2498-2504. 10.1101/gr.1239303

Sivaprasad U, Askew DJ, Ericksen MB, Gibson AM, Stier MT, Brandt EB, Bass SA, Daines MO, Chakir J, Stringer KF, Wert SE, Whitsett JA, Le Cras TD, Wills-Karp M, Silverman GA, and Khurana Hershey GK. 2011. A nonredundant role for mouse SERPINB3A in the induction of mucus production in asthma. Journal of Allergy and Clinical Immunology 127:254-261, 261.e251-256. 10.1016/j.jaci.2010.10.009

Spitzweg C, Joba W, Schriever K, Goellner JR, Morris JC, and Heufelder AE. 1999. Analysis of human sodium iodide symporter immunoreactivity in human exocrine glands. Journal of Clinical Endocrinology and Metabolism 84:4178-4184. 10.1210/jcem.84.11.6117

Steele MA, Croom J, Kahler M, AlZahal O, Hook SE, Plaizier K, and McBride BW. 2011 a. Bovine rumen epithelium undergoes rapid structural adaptations during grain-induced subacute ruminal acidosis. American Journal of Physiology Regulatory Integrative and Comparative Physiology 300:R1515-1523. 10.1152/ajpregu.00120.2010

Steele MA, Dionissopoulos L, AlZahal O, Doelman J, and McBride BW. 2012. Rumen epithelial adaptation to ruminal acidosis in lactating cattle involves the coordinated expression of insulin-like growth factor-binding proteins and a cholesterolgenic enzyme. Journal of Dairy Science 95:318-327. 10.3168/jds.2011-4465

Steele MA, Vandervoort G, AlZahal O, Hook SE, Matthews JC, and McBride BW. 2011 b. Rumen epithelial adaptation to high-grain diets involves the coordinated regulation of genes involved in cholesterol homeostasis. Physiological Genomics 43:308-316. 10.1152/physiolgenomics.00117.2010

Steentoft C, Vakhrushev SY, Joshi HJ, Kong Y, Vester-Christensen MB, Schjoldager KT, Lavrsen K, Dabelsteen S, Pedersen NB, Marcos-Silva L, Gupta R, Bennett EP, Mandel U, Brunak S, Wandall HH, Levery SB, and Clausen H. 2013. Precision mapping of the human O-GalNAc glycoproteome through SimpleCell technology. EMBO Journal 32:1478-1488. 10.1038/emboj.2013.79

Su G, Kuchinsky A, Morris JH, States DJ, and Meng F. 2010. GLay: community structure analysis of biological networks. Bioinformatics 26:3135-3137. 10.1093/bioinformatics/btq596

Tashian RE. 1989. The carbonic anhydrases: Widening perspectives on their evolution, expression and function. Bioessays 10:186-192. 10.1002/bies.950100603

Tong L, Lan W, Lim RR, and Chaurasia SS. 2014. S100A proteins as molecular targets in the ocular surface inflammatory diseases. Ocul Surf 12:23-31. 10.1016/j.jtos.2013.10.001

van Hasselt PM, Ferdinandusse S, Monroe GR, Ruiter JP, Turkenburg M, Geerlings MJ, Duran K, Harakalova M, van der Zwaag B, Monavari AA, Okur I, Sharrard MJ, Cleary M, O'Connell N, Walker V, Rubio-Gozalbo ME, de Vries MC, Visser G, Houwen RH, van der Smagt JJ, Verhoeven-Duif NM, Wanders RJ, and van Haaften G. 2014. Monocarboxylate 
871 transporter 1 deficiency and ketone utilization. New England Journal of Medicine 371:19001907. 10.1056/NEJMoa1407778

van Miert AS, and van Duin CT. 1991. Feed intake and rumen motility in dwarf goats. Effects of some alpha 2-adrenergic agonists, prostaglandins and posterior pituitary hormones. Veterinary Research Communications 15:57-67.

Van Nevel CJ, and Demeyer DI. 1996. Influence of $\mathrm{pH}$ on lipolysis and biohydrogenation of soybean oil by rumen contents in vitro. Reproduction Nutrition Development 36:53-63.

Veenendaal GH, Nijnanten FMAW-V, Duin CTMVAN, and Miert ASJPAMV. 1980. Role of circulating prostaglandins in the genesis of pyrogen (endotoxin)-induced ruminal stasis in conscious goats. Journal of Veterinary Pharmacology and Therapeutics 3:59-68. 10.1111/j.1365-2885.1980.tb00409.x

Venturi S, and Venturi M. 1999. Iodide, thyroid and stomach carcinogenesis: evolutionary story of a primitive antioxidant? European Journal of Endocrinology 140:371-372. 10.1530/eje.0.1400371

Wang G, Xu Z, Wang R, Al-Hijji M, Salit J, Strulovici-Barel Y, Tilley A, Mezey J, and Crystal R. 2012. Genes associated with MUC5AC expression in small airway epithelium of human smokers and non-smokers. BMC Medical Genomics 5:21.

Wang J-H, Zhao L-F, Lin P, Su X-R, Chen S-J, Huang L-Q, Wang H-F, Zhang H, Hu Z-F, Yao K-T, and Huang Z-X. 2014. GenCLiP 2.0: a web server for functional clustering of genes and construction of molecular networks based on free terms. Bioinformatics 30:2534-2536. 10.1093/bioinformatics/btu241

Wang LQ, Baldwin RL, and Jesse BW. 1996. Isolation and characterization of a cDNA clone encoding ovine type I carbonic anhydrase. Journal of Animal Science 74:345-353.

Wang TY, Liu M, Portincasa P, and Wang DQ. 2013. New insights into the molecular mechanism of intestinal fatty acid absorption. European Journal of Clinical Investigation 43:1203-1223. 10.1111/eci.12161

Watson-Haigh NS, Kadarmideen HN, and Reverter A. 2010. PCIT: an R package for weighted gene co-expression networks based on partial correlation and information theory approaches. Bioinformatics 26:411-413. 10.1093/bioinformatics/btp674

Weaver BP, Dufner-Beattie J, Kambe T, and Andrews GK. 2007. Novel zinc-responsive posttranscriptional mechanisms reciprocally regulate expression of the mouse SLC39A4 and SLC39A5 zinc transporters (Zip4 and Zip5). Biological Chemistry 388:1301-1312. 10.1515/bc. 2007.149

Wrong OM, and Vince A. 1984. Urea and ammonia metabolism in the human large intestine. Proceedings of the Nutrition Society 43:77-86.

Young JW. 1977. Gluconeogenesis in Cattle: Significance and Methodology. Journal of Dairy Science 60:1-15. 10.3168/jds.S0022-0302(77)83821-6

Yu Z, Wildermoth JE, Wallace OAM, Gordon SW, Maqbool NJ, Maclean PH, Nixon AJ, and Pearson AJ. 2011. Annotation of sheep keratin intermediate filament genes and their patterns of expression. Experimental Dermatology 20:582-588. 10.1111/j.16000625.2011.01274.x 
Table $\mathbf{1}$ (on next page)

Gene Ontology enrichments of clusters 
1 Table 1 Gene Ontology enrichments of clusters

\begin{tabular}{lll}
\hline Cluster & GO-term & $\begin{array}{l}\text { FDR corrected } \boldsymbol{P} \text { - } \\
\text { value }^{\mathbf{1}}\end{array}$ \\
\hline Rumen & EDC locus $^{2}$ & $7.1 \mathrm{E}-13^{3}$ \\
Epithelia-rumen-tonsil & EDC locus & $8.6 \mathrm{E}-15^{3}$ \\
& Defense response to fungus & $8.6 \mathrm{E}-03$ \\
Epithelia-rumen bias & Keratinization & $2.4 \mathrm{E}-04$ \\
Epithelia-all & - & - \\
Epithelia-large intestine & Desmosome organization & $4.7 \mathrm{E}-03$ \\
Epithelia-GI-liver & Cell junction organization & $6.3 \mathrm{E}-03$ \\
Abomasum-intestine & - & - \\
Intestine-low in rectum & - & - \\
Large intestine & Regulation of chloride & $4.5 \mathrm{E}-05$ \\
& transport & - \\
Intestine & - & $1.4 \mathrm{E}-46$ \\
Epithelia-intestine & Cell cycle process & $3.8 \mathrm{E}-02$ \\
Abomasum & Digestion & - \\
Small intestine & - & $2.2 \mathrm{E}-04$ \\
Rumen-abomasum & Platelet aggregation & $5.5 \mathrm{E}-10$ \\
Rumen-intestine-liver & Flavonoid biosynthetic process \\
Intestine-spleen & Humoral immune response & $4.5 \mathrm{E}-02$ \\
\hline
\end{tabular}

${ }^{1}$ Top significantly enriched pathway selected from GORILLA analysis (see methods) for each input gene cluster

${ }^{2}$ Genes in the EDC locus of the sheep genome.

${ }^{3}$ Enrichment of EDC locus genes was calculated using the hypergeometric distribution. 


\section{Table 2 (on next page)}

Representation of the pig GIT gene clusters in the sheep GIT network 
1 Table 2 Representation of the pig GIT gene clusters in the sheep GIT network

\begin{tabular}{|c|c|c|c|c|c|c|c|c|}
\hline Pig cluster $^{1}$ & Pig tissues $^{1}$ & $\begin{array}{l}\text { Pig cell type of } \\
\text { origin }^{2}\end{array}$ & Overlap & $P$-value ${ }^{2}$ & Representation & Sheep tissues & Go term enrichment & $P$-value ${ }^{3}$ \\
\hline Overall & & & 179 & $8.1 \mathrm{E}-31$ & Over & & Cell cycle process & $2.0 \mathrm{E}-13$ \\
\hline 1,7 & Intestine - & $\begin{array}{l}\text { Immune cells/cell } \\
\text { cycle }\end{array}$ & 58 & $2.4 \mathrm{E}-11$ & Over & Epithelia, intestine & Cell cycle process & $1.5 \mathrm{E}-33$ \\
\hline 3,8 & $\begin{array}{l}\text { Tongue- } \\
\text { oesophagus }\end{array}$ & $\begin{array}{l}\text { Stratified squamous } \\
\text { epithelia }\end{array}$ & 73 & $1.3 \mathrm{E}-34$ & Over & $\begin{array}{l}\text { Rumen, epithelia, } \\
\text { abomasum, large } \\
\text { intestine }\end{array}$ & Epidermis development & $2.9 \mathrm{E}-05$ \\
\hline $2,4,9$ & $\begin{array}{l}\text { Oesophagus- } \\
\text { stomach }\end{array}$ & Muscle & 9 & $0.0002^{4}$ & Under $^{4}$ & Rumen, abomasum & na & \\
\hline $6,13,15$ & Salivary gland & $\begin{array}{l}\text { Stratified columnar } \\
\text { epithelia }\end{array}$ & 4 & 0.1777 & None & & na & \\
\hline $5,12,14,16$ & $\begin{array}{l}\text { Stomach- } \\
\text { intestine }\end{array}$ & $\begin{array}{l}\text { Ciliate/glandular } \\
\text { epithelia }\end{array}$ & 35 & 5.4E-09 & Over & Stomach intestine & na & \\
\hline 10 & Stomach & Neuronal & 0 & na & na & & na & \\
\hline
\end{tabular}

2 Numbers, names and grouping of pig gene clusters by cell type of origin are according to (Freeman et al. 2012).

${ }^{2}$ Calculated hypogeometric $P$ values, representing the significance of representation of pig genes in sheep gene network.

${ }^{3}$ FDR corrected GO term enrichment $P$ values.

${ }^{4}$ If overlap with just the rumen and rumen-abomasum clusters, significant $(P=8 \mathrm{E}-05)$ over representation 


\section{Figure 1 (on next page)}

Transcriptomic sample clustering.

Each dot represents one tissue sample from a single animal. Circles indicate significant clusters (confidence interval $=95 \%$ ). Raw PCA plots are available (Additional file 2: Figure S1). 


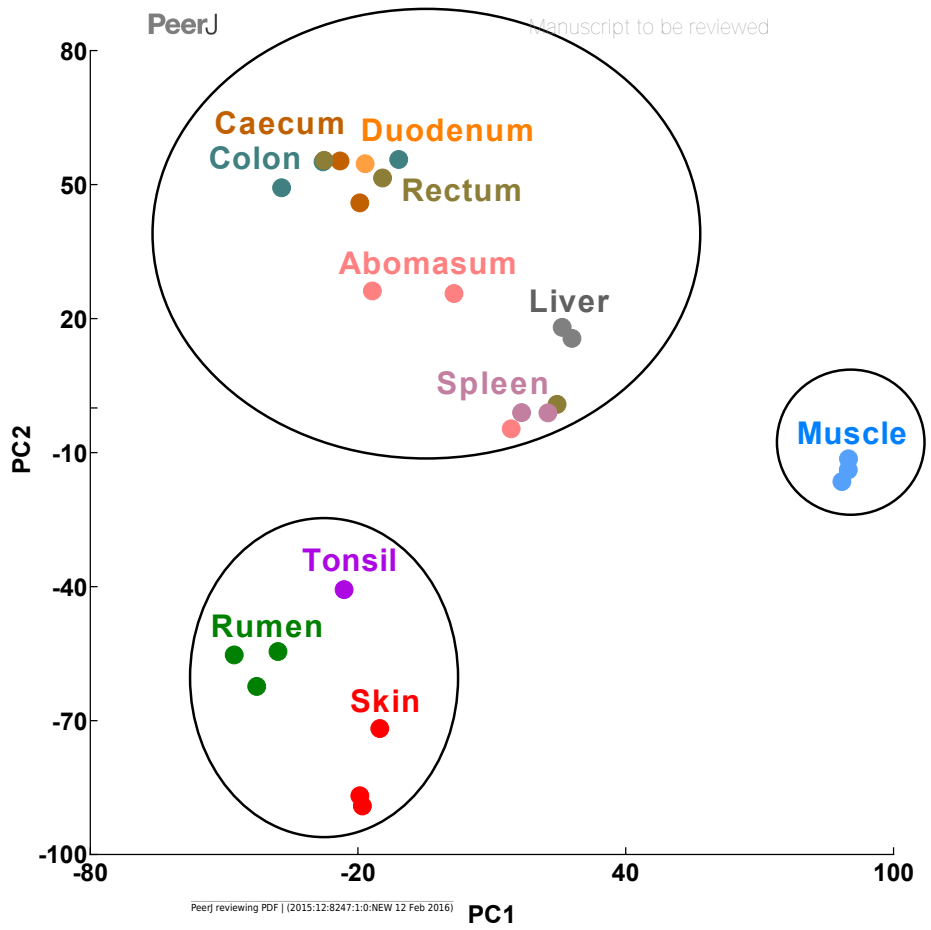


Figure 2 (on next page)

Gene co-expression network.

(A) Each dot represents a sheep transcript and different colors represent the tissue(s) where the transcript showed high expression, compared to the other tissues. Rectum $\downarrow$ : low in rectum. (B) The same gene co-expression network with only the orthologous genes present in specific pig GIT clusters (Freeman et al. 2012) highlighted (Additional file 1). The names and colors of pig cluster were determined according to the tissues where genes showed the highest and the second highest expression level in the pig Gl gene network (Freeman et al. 2012) . 
ApeerJ

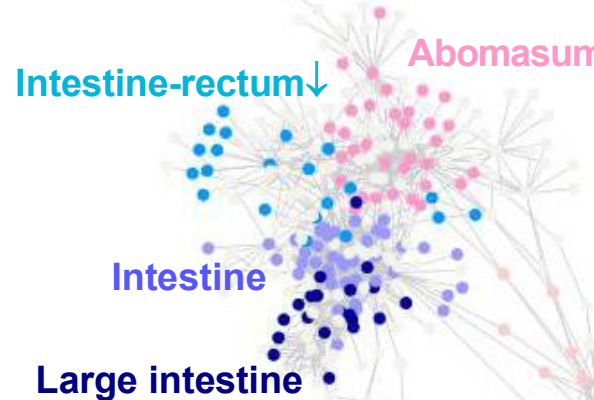

\section{Epithelia-GI-liver}

Intestine-spleen Rumen-abomasum
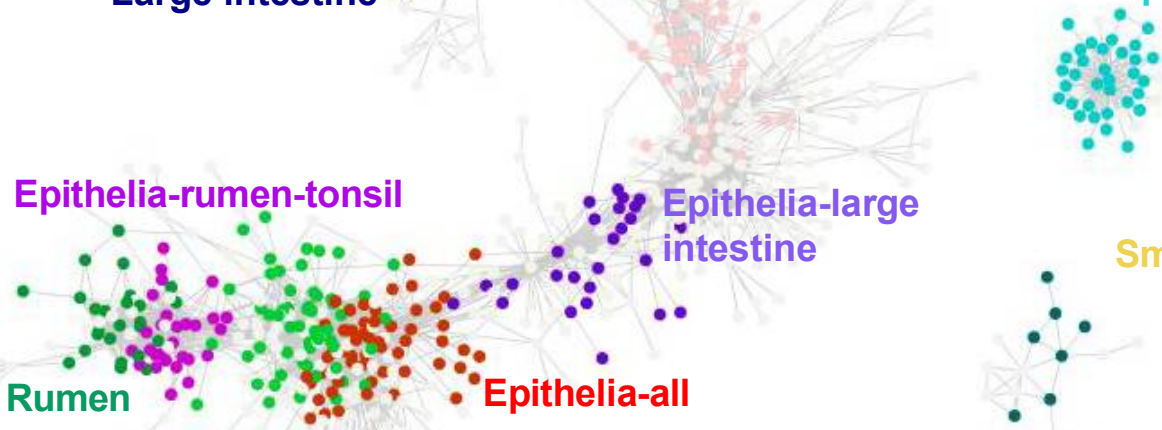

Epithelia-rumen-bias

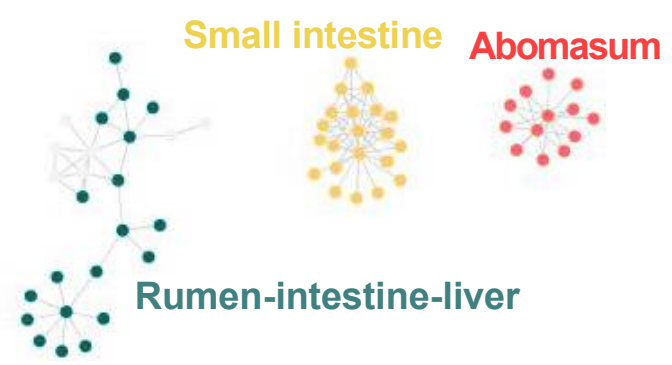

B

Tongue-oesophagus

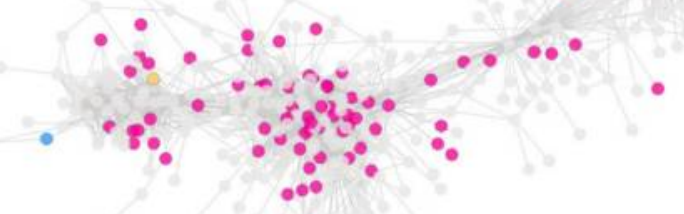

Salivary gland 
Figure 3 (on next page)

Expression profiles of innate immunity and epithelial development genes in sheep.

Data are presented with $\log _{2}$ Fragments Per Kilobase of exon per Million fragments mapped (FPKM) values along with the subcellular locations and/or tissues of pig (Freeman et al. 2012) and human (Genevestigator (Hruz et al. 2008) analysis) where these genes showed high expression. Cellular location information were derived from GENATLAS database (Frezal 1998) . 
Cellular location Human tissue

Cytoplasm

Extracellular

Golgi

Intracellular

Intermed filament Intermed filament Intermed filament Intermed filament

Extracellular

Extracellular

Extracellular

Apical

Intracellular

Apical

-

Intracellular

Intracellular

Intracellular

intritracellular

Apical

Apical

Intracellular

Intracellular

Intracellular
Mouth

General

Mouth

Epidermis

lleum/colon

Colon

Ileum/colon

Tongue

Mouth

Mouth

Salivary gland/skin

Lymphocytes/heart

Epidermis

Epithelia/ileum/colon

Epithelia/ileum/colon

Pharynx

Mouth

Epidermis

Epidermis

Epidermis

Epidermis

Tongue/monocytes

Monocytes/mouth

Bone marrow/monocytes

\section{Pig tissue}

Tongue-oesophagus

-

Tongue-oesophagus Tongue-oesophagus

Tongue-oesophagus

-

Salivary gland

Tongue-oesophagus

Tongue-oesophagus

-

$-$

-

-

Tongue-oesophagus

-

Tongue-oesophagus

Tongue-oesophagus

Tongue-oesophagus

Tongue-oesophagus

Tongue-oesophagus 
Figure 4 (on next page)

Gene expression profiles of metabolic processes discussed in the text.

Data are presented with $\log _{2}$ Fragments Per Kilobase of exon per Million fragments mapped (FPKM) values along with the subcellular locations and/or tissues of pig (Freeman et al. 2012) and human (Genevestigator (Hruz et al. 2008) analysis) where these genes showed high expression. Texts and bars on the left side of the heatmap indicate involved pathways for covered genes described in the article. Cellular location information were derived from GENATLAS database (Frezal 1998). 


\section{Figure 4 \\ PeerJ}

$\log _{2}$ (FPKM)

\begin{tabular}{llll}
\hline-8.8 & 0 & 3 & 12.3
\end{tabular}

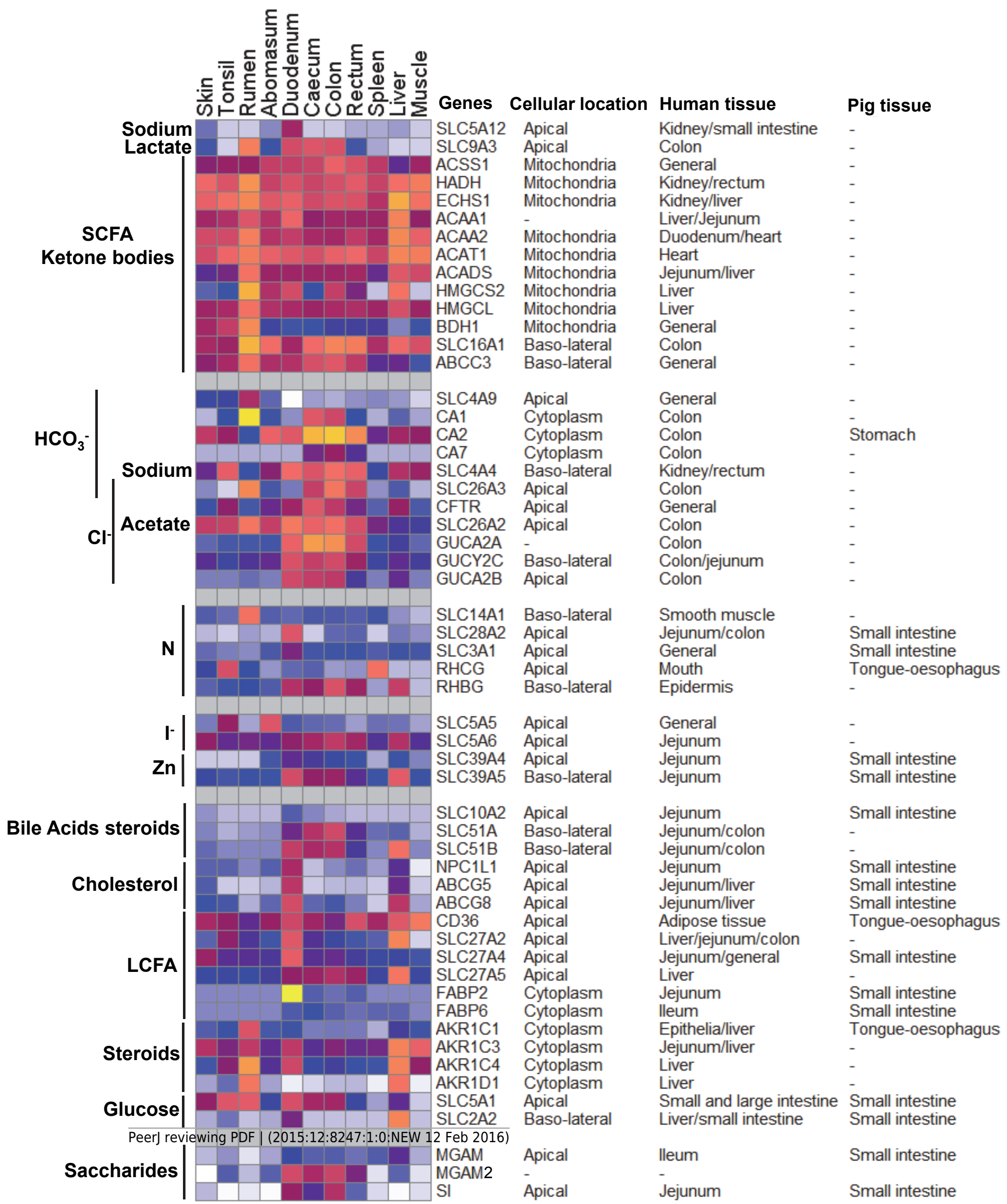




\section{Figure $\mathbf{5}$ (on next page)}

Ruminant ketone body metabolism pathways.

Key enzyme encoding genes (red text) and pathways (black arrow) are highlighted. 


\section{Acetate}

\section{Butyrate}

PeerJ

$$
\begin{array}{cc}
\text { ACSS1 } \\
\text { Acetyl-CoA }
\end{array}
$$

\section{Acetoacetyl-CoA}

HMGCS2

3-hydroxymethyl-glutaryl-CoA

\section{HMGCL}

Acetyl-CoA Acetoacetate

Succinate

OXCT1

Succinyl-CoA

\section{D(-)-3-hydroxybutyrate}




\section{Figure 6 (on next page)}

Organization of the MGAM2 carboxy-teminus.

Consensus motifs of the serine/threonine rich 40 amino acid repeats at the carboxy-terminus of predicted MGAM-like proteins. (A) sheep. (B) cattle. (C) Pig. (D) human. 


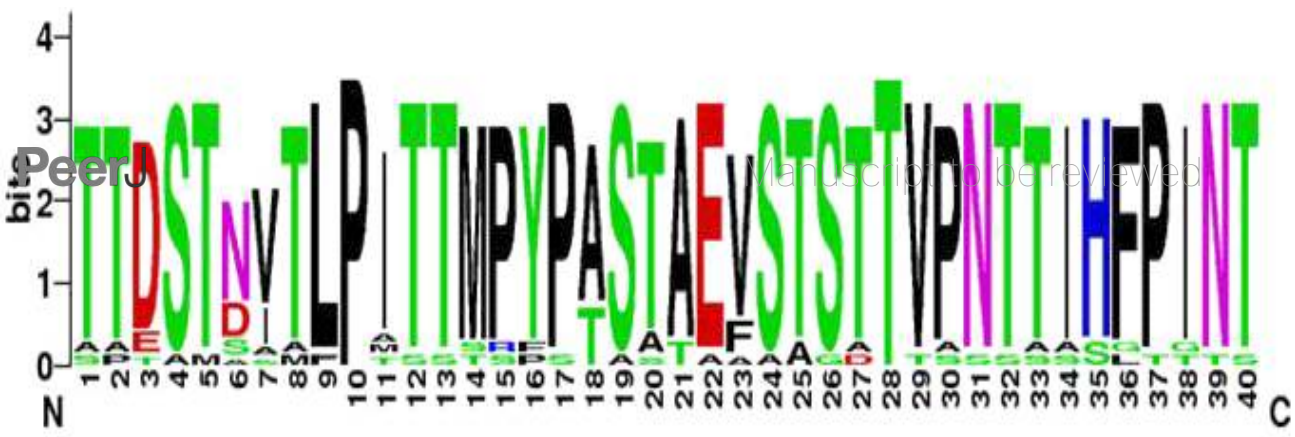

\section{Cattle MGAM-like protein amino acid repeats}

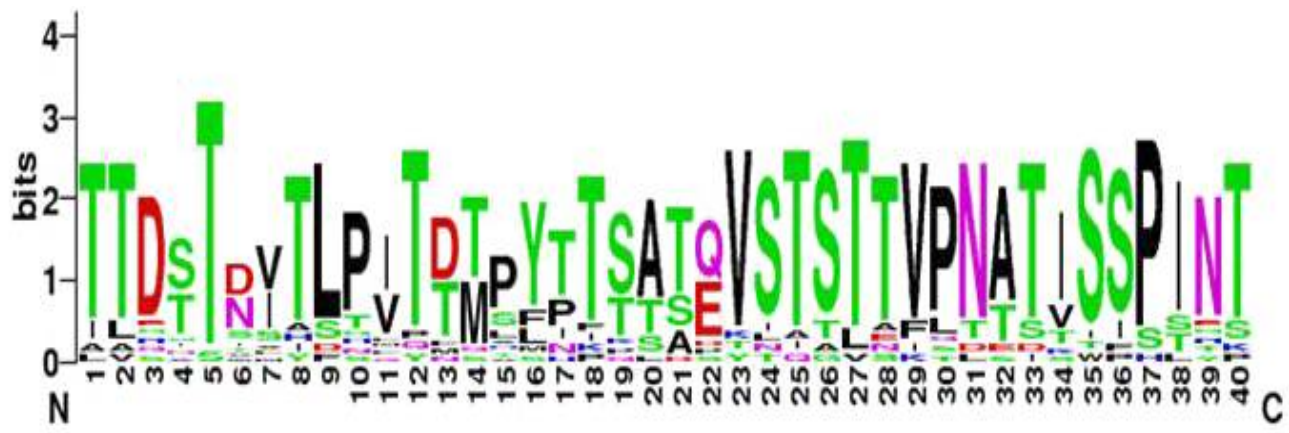

Pig MGAM-like protein amino acid repeats

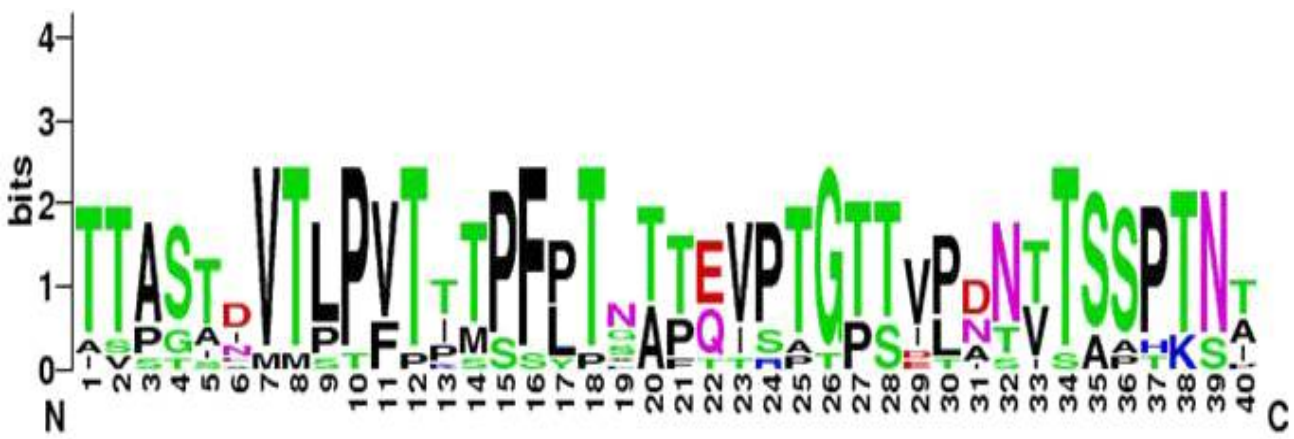

D Human MGAM-like protein amino acid repeats

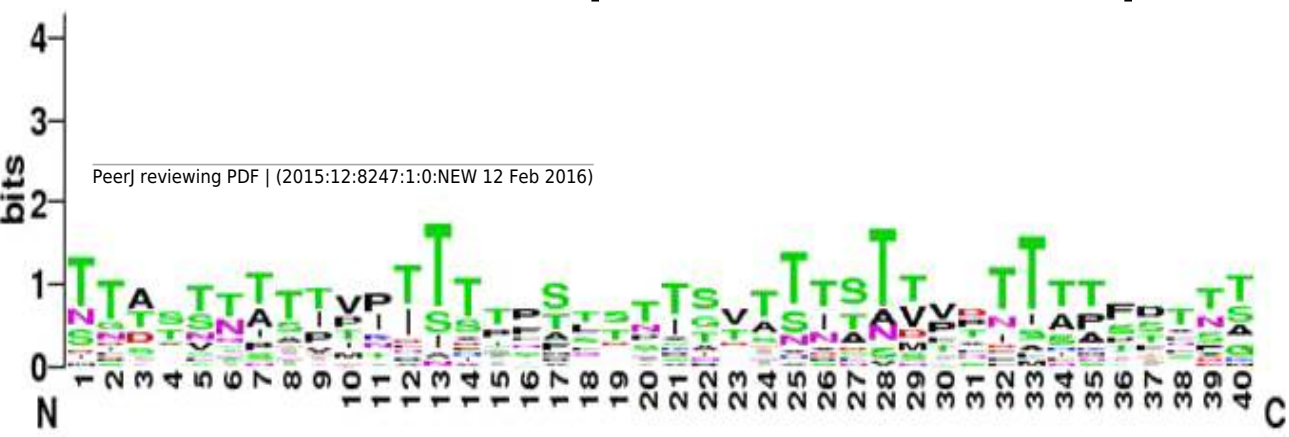

